\title{
When a gain becomes a loss: The effect of wealth predictions on financial decisions
}

\author{
Jennifer S. Trueblood \\ Department of Psychology, Vanderbilt University \\ Abigail B. Sussman \\ University of Chicago Booth School of Business
}

Corresponding Author:

Jennifer Trueblood

Department of Psychology

Vanderbilt University

PMB 407817

2301 Vanderbilt Place

Nashville, TN 37240-7817

email: jennifer.s.trueblood@vanderbilt.edu

This work was supported by the National Science Foundation (1846764) and by the True North Communications, Inc. Fund and the Fama-Miller Center at the University of Chicago Booth School of Business. 


\begin{abstract}
When people make financial decisions, they need not only think about their current financial situation, but also about changes in future wealth. This work investigates people's beliefs about their future wealth and how these beliefs impact financial decisions. Using a joint experimental and computational cognitive modeling approach, we show that people's future beliefs serve as reference points when making investment decisions. These results are further supported by data from a largescale cross-sectional survey $(n=4,606)$ showing that people's beliefs about the future value of their assets are related to investment decisions between risky (i.e., stock market index) and safe (i.e., bond earning a fixed amount per year) options. In both the experiments and survey, we hypothesize that outcomes that are nominally stated as sure gains can become coded as losses due to belief-based reference points. This pattern leads to an increase in riskier choices across positive outcomes for individuals with optimistic beliefs about their future wealth.
\end{abstract}

Keywords: financial decision-making, risk-taking, reference points, Prospect Theory, prediction, expectations 


\section{Introduction}

Financial decisions are often made with future goals in mind. People may want to have enough money to take a vacation next summer or buy a new home in five years. More broadly, nearly all financial decisions impact the future. As such, beliefs about future wealth (i.e., a person's expectations about their assets and debts) may play a significant role in many financial decisions. For example, a person's decision to invest part of their assets in a risky option over a safer one might depend not only on their risk attitudes and expectations about the performance of the assets, but also on their expectations about future changes to their own financial state.

Although most financial decisions involve thinking about the future, relatively little work has examined how people's beliefs about their future wealth impact the financial decisions they make today. We propose that these beliefs serve as reference points (Tversky \& Kahneman, 1992) and that they alter risk attitudes. Consequently, options presented as sure gains in absolute terms may be perceived as psychological losses relative to expectations about future wealth. This interpretation of the options may lead people to select risky options to avoid the possibility of a sure (psychological) loss.

To study the link between beliefs and financial decisions, our first two experiments investigate investment decisions involving a choice between two products: a basic low risk, low-return interestbased savings account and a higher-risk, higher-return prize-linked savings (PLS) account. We select the PLS account as the risky option given growing interest in the use of these accounts to increase household savings rates (they are currently legal in about half of US states), particularly among low-income households (Kearney, Tufano, Guryan, \& Hurst, 2010; Tufano, De Neve, \& Maynard, 2011; Atalay, Bakhtiar, Cheung, \& Slonim, 2014). The PLS account returns principal but does not offer interest. Instead, it incorporates a lottery-like drawing with a low probability of a large potential upside. Thus, a decision between a basic interest-based savings account (for example, offering a fixed $2 \%$ rate of return) and a PLS account offering no interest but the chance to win a large amount of money is akin to the decision between a "sure thing" and a risky gamble.

On the surface, the decision between the PLS and basic interest-based savings account might appear as a choice between two gains (a small sure one and a large risky one). Regardless of the account people select, they cannot lose money relative to their initial investment. However, interpretation of gains versus losses depends on the decision maker's reference point (Tversky \& 
Kahneman, 1992), and an account of the choice as one between gains relies on a $\$ 0$ reference point. Instead, suppose that people generally expect that their wealth will increase in the future. If people rely on their expectation of their assets' future growth as an alternative reference point, it becomes less clear if the decision problem is operating in the domain of gains. If the interest-based savings account offers a $2 \%$ rate of return, but people generally believe their assets will grow faster than that rate, then investing a portion of their current assets in this account could psychologically appear as a loss.

Further, using data from a large-scale cross-sectional survey, we show that the results from our experiments examining decisions between PLS and basic interest-based savings accounts generalize to decisions about stock market investments. In the survey, participants are asked to allocate a hypothetical $\$ 1000$ between a US stock market index and a bond earning $2 \%$ per year. Similar to an interest-based savings account offering a $2 \%$ rate of return, we hypothesize that a bond earning $2 \%$ per year could psychologically appear as a loss if a person believes their assets will grow faster than $2 \%$. Thus, what objectively appears to be a choice between a small sure gain (i.e., the bond) and a risky gamble (i.e., stock market index) might psychologically appear as a decision between a small sure loss and a gamble for people with optimistic beliefs about their future wealth.

The current work builds on research investigating the impact of expectations on financial decisions. In the context of individual financial decision making, research has primarily focused on how expectations about the performance of financial products influence decisions about those products (Greenwood \& Shleifer, 2014; Choi, Laibson, Madrian, \& Metrick, 2009). However, there are two major limitations to this work. First, expectations about financial product performance represent only one type of belief that individuals could bring to bear on financial decisions. Here, we investigate how people's general beliefs about the future state of their finances impact their financial decisions today. Second, relatively few studies have addressed the mechanism through which beliefs guide financial decisions. Most of the research in this area has simply shown correlations between expectations and behavior (e.g., Greenwood \& Shleifer, 2014). One notable exception is research by Malmendier and Nagel (2011) showing that people who live through macroeconomic shocks become more risk averse, known as the "depression babies effect". Their work suggests that the effect is driven by changes in beliefs about the future.

Consistent with Malmendier and Nagel (2011), we hypothesize that beliefs serve as refer- 
ence points. Tversky and Kahneman $(1991,1992)$ originally suggested that people make decisions with respect to reference points. However, they did not undertake a detailed investigation of where reference points come from. Rather, they suggested that reference states generally correspond to an individual's current wealth and could also be influenced by norms, aspirations, and expectations. Recent research in behavioral economics suggests that that reference points often come from expectations (Abeler, Falk, Goette, \& Huffman, 2011; Bartling, Brandes, \& Schunk, 2015; Bell, 1985; Gul et al., 1991; Kőszegi \& Rabin, 2006, 2007, 2009; Pope \& Schweitzer, 2011; Loomes \& Sugden, 1986; Marzilli Ericson \& Fuster, 2011). While this work has shown important evidence of expectations-based reference-dependent preferences, almost every demonstration of the theory has relied on manipulations of people's expectations (e.g., manipulating incentives in real-effort tasks, Abeler et al., 2011). Evidence for self generated reference points (without experimental manipulation) comes from research on goals and aspirations (e.g., Heath, Larrick, \& Wu, 1999). For example, Markle, Wu, White, and Sackett (2018) found that marathon runners' finishing time goals serve as reference points when judging their satisfaction with actual finishing times. The present study extends these results by showing that people's beliefs about their future wealth can also serve as reference points influencing financial decisions.

The paper is structured as follows. In two experiments, people make judgments about the future value of assets and debts along with investment decisions for a range of financial profiles (where profiles are described in terms of total assets and debt, for example $\$ 67,000$ in assets and $\$ 1,000$ in debt). Using computational modeling, we test the hypothesis that people's beliefs serve as reference points when making investment decisions. We propose alternative reference point models and find that the belief-based reference point model provides the best accounting of our data. In a third experiment, we use data from the Panel Study of Income Dynamics (2021) to examine whether judgments are biased or consistent with real world trends. In a fourth study, we use data from a largescale cross-sectional survey (with over 4,000 participants) to show that people's predicted change in the future value of their assets is associated with investment decisions in the US stock market, in line with our hypothesis of belief-based reference points.

Data from all studies along with model code is available on the Open Science Framework at http://bit.ly/2piKB43. 


\section{Experiment 1}

Experiment 1 investigates people's beliefs about future wealth and the potential consequences of these beliefs on financial decisions. Based on decades of research showing that people are overly optimistic about future life events (e.g., owning your own home, living past 80, getting a good job offer before graduation; Weinstein, 1980; Weinstein \& Lachendro, 1982; Puri \& Robinson, 2007; Shepperd, Klein, Waters, \& Weinstein, 2013), we hypothesize that people will have optimistic beliefs about future wealth. In addition to making predictions, participants also make a series of investment decisions involving a "safe" (basic savings) account and a "risky" (PLS) account. This data is used to test the hypothesis that beliefs act as reference points in financial decision-making.

\section{Methods}

Participants. 196 Amazon Mechanical Turk participants completed the experiment in exchange for $\$ 1.00$ in October 2018. We set a sample size of approximately 100 participants per condition and the experiment had two between-subjects conditions. We selected this sample size in order to have sufficient data for computational modeling using hierarchical Bayesian methods. Sample size was predetermined before running the experiment, and we did not analyze data until all of the data had been collected.

Materials. The stimuli consisted of 40 financial profiles, described as total assets and debts (as in Sussman \& Shafir, 2012). Participants were asked to imagine that the profiles described their financial situation. The 40 profiles were made up of 20 positive net worth profiles and 20 negative net worth profiles. The type of profile (positive or negative) was a between-subjects condition. Net worth was fixed for all of the profiles in a given set. Specifically, the net worth for all profiles in the positive (negative) set was $\$ 66,000(-\$ 66,000)$. The values of assets and debts varied across profiles in each set from profiles with small assets and debt (e.g., assets $=\$ 67,000$, debt $=\$ 1,000$ in the positive set) to profiles with large assets and debt (e.g., assets $=\$ 257,000$, debt $=\$ 191,000$ in the positive set). The negative profiles were created by reversing the assets and debts from the positive profiles. That is, the assets (debts) from the positive set became the debts (assets) in the negative set. A complete list of the positive net worth profiles used in this experiment are in the Supplementary Materials.

The 40 profiles were used in two tasks: a prediction task and an investment decision task. 
In the investment decision task, participants were presented with a profile and a choice between investing half of their assets in one of two different savings accounts. One of the accounts was described as offering interest of $2 \%$ annually. The other account was a PLS account, offering no interest but a $0.8 \%$ chance of winning a large amount of money in one year. This amount was selected so that the expected value of the PLS account was the same as the interest earned from the interest-based savings account offering $2 \%$ annually.

Procedure. At the start of the experiment, participants were randomly assigned to either the positive or negative net worth condition. Participants completed both the prediction and investment decision tasks using the 20 profiles for their condition. The order of the two tasks was randomized (half of participants completed the prediction task before the investment decision task and vice versa), with a distractor task in between involving classification decisions about images of US National Parks.

For the prediction task, participants were instructed that on each trial they would see a financial profile (described as assets and debt) that described their financial situation Their task was to predict the future value of their assets and debts one year from now. Participants were told to imagine that they had steady jobs and did not anticipate any unusual expenses in the upcoming year. Participants were also told that there were no right or wrong responses.

Participants provided separate estimates for future assets and future debts by typing their predictions into a text box. Before starting the main task, participants completed one guided practice trial on how to enter numbers into the text box. After completing the practice question, participants made two predictions (one for assets and one for debts) for each of the 20 profiles (either all positive or all negative) for a total of 40 predictions per participant. An example question is provided below:

Imagine that you have $\$ 67,000$ in assets, and $\$ 1,000$ in debt.

In 1 year, what do you estimate your assets will be?

In 1 year, what do you estimate your debt will be?

At the start of the investment decision task, participants were instructed that on each trial they would have the opportunity to invest half of their assets in one of two bank accounts. They were told that one of the bank accounts offered interest of $2 \%$ annually. The other bank account offered no interest payments, but a $0.8 \%$ chance of winning a large amount of money in one year. To help 
clarify the probability of winning, participants were also provided this information as a frequency (that is, 1 out of 125 people win). Before starting the task, participants read the following example situation:

For example, if you invest $\$ 1,000$ in the interest-based savings account, you will earn $\$ 20(2 \%$ of $\$ 1,000)$ in one year. Alternatively, if you invest the $\$ 1,000$ in the prize-linked savings account, you will have a $0.8 \%$ chance (1 out of 125) of winning \$2500 in one year, but no interest.

After reading the instructions and example situation, participants made investment decisions for each of the 20 profiles (either all positive or all negative). An example question is provided below: Imagine that you have $\$ 67,000$ in assets and \$1,000 in debt. You plan to invest half of your assets. Which bank account do you prefer?

Savings Account A: 2\% annual interest, earning $\$ 670$ in one year Savings Account B: $0.8 \%$ chance of winning $\$ 83,750$ in one year with no interest

The order of the two savings accounts in each question (i.e., which one was listed as A or B) was randomized. The order of the 20 investment choices was also randomized.

Results

Behavioral Results. For the data analyses below, we excluded participants with multiple extreme predictions. Specifically, the exclusion criterion was having 10 out of 40 responses (or $25 \%$ ) that were three scaled median absolute deviations away from the median response for a given question. Typically, these participants provided very extreme responses (e.g., very small responses such as ' 20 ' or extremely large responses such as '2,400,000’ for most questions). This removed 45 participants, leaving 151 for the data analyses.

First, we conducted four Wilcoxon signed rank tests (one for each condition: positive/negative net worth $\times$ assets/debt) to determine whether participants' future predictions were generally larger or smaller than the given present values. Participants' predictions for assets were generally larger than present values for both positive $(Z=22.48, p<.001)$ and negative $(Z=10.64$, $\mathrm{p}<.001$ ) net worth profiles. Across the 20 asset questions in each condition, the average difference between predictions and present values was greater than zero for most participants $(82.2 \%$ of participants in the positive net worth condition and $69.4 \%$ of participants in the negative net worth 
condition). Participants' predictions for debts were generally smaller than present values for both positive $(Z=-22.78, p<.001)$ and negative $(Z=-19.42, p<.001)$ net worth profiles. Across the 20 debt questions in each condition, the average difference between predictions and present values was less than zero for most participants $(78.5 \%$ of participants in the positive net worth condition and $76.4 \%$ of participants in the negative net worth condition).

To further investigate participants' predictions, we calculated the growth rate for assets and debts for each profile, where the growth rate is defined as

$$
\text { growth rate }=\frac{\text { Future Value }- \text { Present Value }}{\text { Present Value }}
$$

where 'Future Value' is the participant's prediction and 'Present Value' is the given assets or debt. We then fit a three parameter exponential curve to the median growth rates for each of the four sets of predictions (positive, negative $\times$ assets, debt):

$$
\text { Median Growth Rate }=a+b e^{r x}
$$

where $x$ is the given value of assets or debts, $a$ is the horizontal asymptote, $b$ is a scale factor, and $r$ is the rate. If $a$ and $b$ are positive, then this indicates growth rates are increasing (i.e., assets and debts are predicted to grow in one year). If $a$ and $b$ are negative, then this indicates that growth rates are decreasing (i.e., assets and debts are predicted to shrink in one year). If $r$ is negative, then growth rates are more extreme for small assets and small debts. As seen in Figure 1, assets in both positive and negative net worth conditions are generally predicted to grow (i.e., data and fitted curve are above zero). This is supported by positive parameter estimates for $a$ and $b$ (see Table 1 for parameter estimates). Debts in both the positive and negative net worth conditions are generally predicted to shrink (i.e., data and fitted curve are below zero). This is supported by negative parameter estimates for $a$ and $b$. These results are consistent with optimistic relative judgments in other areas (Weinstein, 1980; Weinstein \& Lachendro, 1982; Shepperd et al., 2013). In addition, participants predicted more extreme changes for small assets and small debts (supported by negative $r$ values in all cases).

Next, we examined people's choices on the investment decision task. There were no differences in choice behavior by task order (i.e., whether participants performed the investment decision 

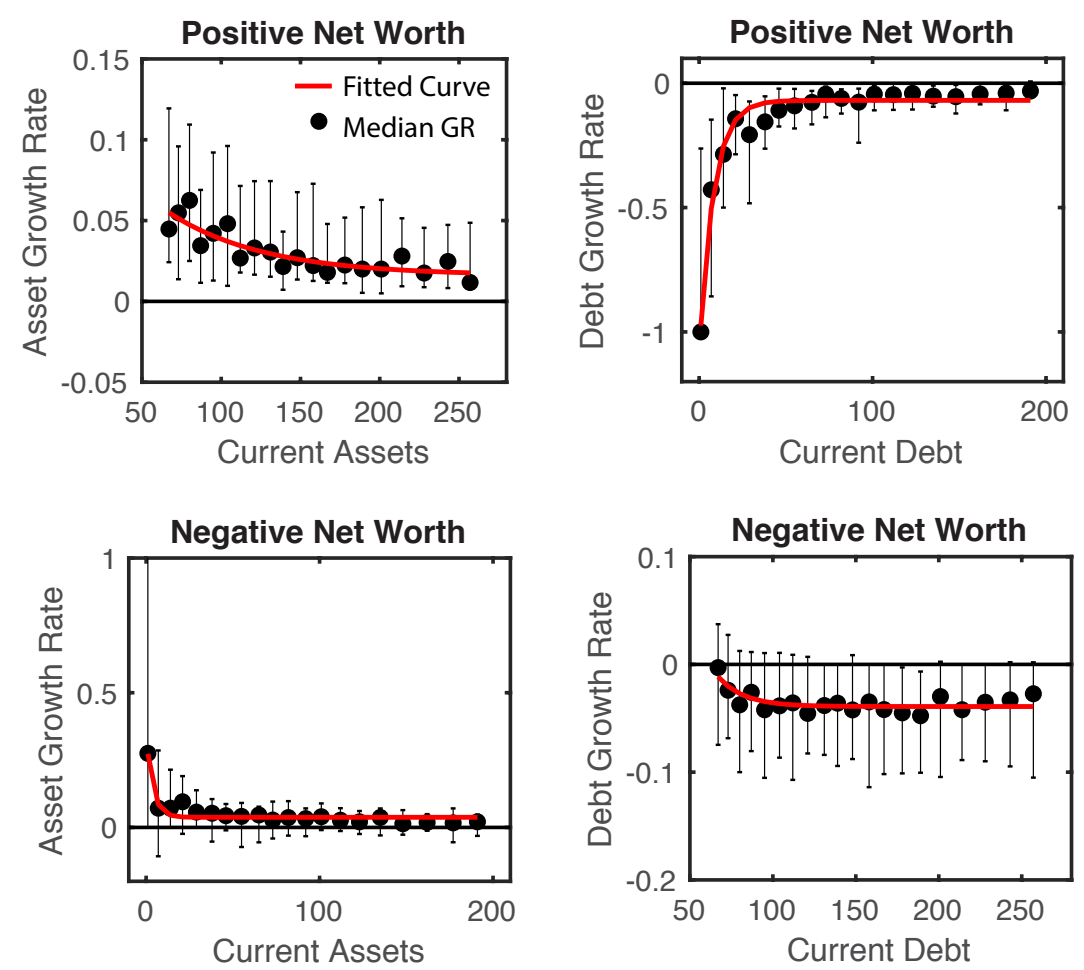

Figure 1. : Growth rates calculated from prediction data in Experiment 1 for assets and debts in the positive and negative net worth conditions. The $\mathrm{x}$-axis is the given value of assets/debts. The black points are the median predictions and the error bars represent the 0.25 and 0.75 quantiles. The red curve is the best fitting exponential function to the median growth rates.

Table 1:: Parameter Estimates for Exponential fit to Growth Rates from Experiment 1. 95\% confidence intervals are in parentheses.

\begin{tabular}{ccccc}
\hline Profile & $\mathrm{a}$ & $\mathrm{b}$ & $\mathrm{r}$ & $R^{2}$ \\
\hline Positive Assets & $0.016(0.004,0.028)$ & $0.118(0.007,0.229)$ & $-0.017(-0.031,-0.002)$ & 0.75 \\
Positive Debt & $-0.069(-0.093,-0.045)$ & $-1.024(-1.140,-0.907)$ & $-0.122(-0.150,-0.095)$ & 0.97 \\
Negative Assets & $0.038(0.027,0.048)$ & $0.307(0.230,0.385)$ & $-0.266(-0.414,-0.117)$ & 0.88 \\
Negative Debt & $-0.039(-0.043,-0.035)$ & $2.000(-6.866,10.870)$ & $-0.064(-0.127,-0.001)$ & 0.59 \\
\hline
\end{tabular}

task before or after the prediction task), $\mathrm{t}(77)=0.15, \mathrm{p}=0.878$ for the positive net worth condition and $\mathrm{t}(70)=0.12, \mathrm{p}=0.902$ for the negative net worth condition. Thus, we collapsed across both orders for the following analysis. As shown in Figure 2 left panel, people were typically risk averse, preferring the interest-based account to the PLS account (mean choice proportion for the PLS account was 0.36 for the positive net worth profiles and 0.39 for the negative net worth profiles). To 
further investigate the relationship between preferences and the characteristics of the financial profiles, we fit a generalized linear mixed-effects model (GLMM) to the choice proportions for the PLS account with four fixed effects predictors, asset amount (in dollars), net worth (in dollars), and their interaction plus a fixed intercept. For this analysis, we used a probit link function and allowed for by-item (i.e., profile) random intercepts. Results showed that choice proportions for the PLS account differed significantly by asset amount $(\beta=-0.003, \mathrm{t}(36)=-7.66, \mathrm{p}<0.001,95 \% \mathrm{CI}$ $[-0.004,-0.002])$, suggesting that the PLS account was more often preferred when assets were small as compared to large. There was no effect of net worth $(\beta=-0.001, \mathrm{t}(36)=-1.60, \mathrm{p}=0.118,95 \%$ CI [-0.003, 0.0003]). However, the interaction between asset amount and net worth was significant $(\beta=.00002, \mathrm{t}(36)=3.24, \mathrm{p}=0.003,95 \% \mathrm{CI}[.000007, .00003])$, showing that choices for the PLS account were more sensitive to the asset values for negative net worth profiles as compared to positive net worth profiles. This is illustrated in Figure 2 where risky choices (i.e., choices for the PLS account) were the largest for the low asset profiles in the negative net worth condition.
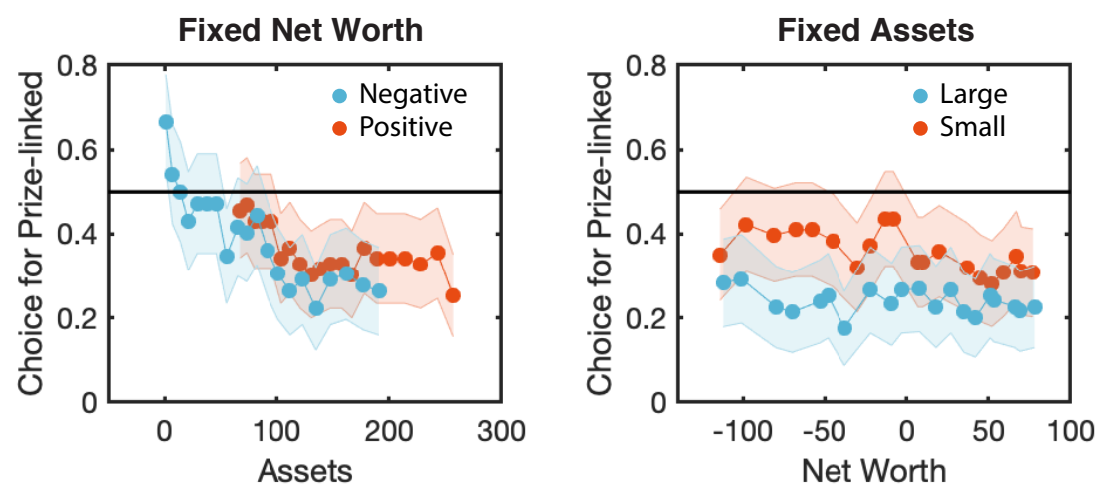

Figure 2. : Choice proportions for the prize-linked savings account option in Experiments 1 and 2. Left panel: Experiment 1 results for each profile plotted separately for positive net worth (orange) and negative net worth (blue) conditions. Right panel: Experiment 2 results for each profile plotted separately for large (blue) and small (orange) conditions. Error bands show 95\% confidence intervals.

Modeling Results. To investigate the relationship between predicted growth rates and choices on the investment decision task, we fit three different versions of Cumulative Prospect Theory (CPT; Tversky \& Kahneman, 1992) to the choice data, each making a different assumption about the reference point in the value function. In the investment decision task, participants made a choice between an interest-based investment account and a PLS account. We assume that this decision can 
be explained by CPT where people assign a subjective value, $V(\cdot)$, to each savings account option.

In CPT, outcomes are transformed into psychology values through a valuation function. In our task, the interest-based savings account (denoted $I$ ) is a "sure thing", offering a guaranteed amount of annual interest. The PLS account (denoted $P$ ) is a risky option, offering a large amount with a .008 probability. Let $x_{i}^{j}$ be the amount offered by savings account $j$ (either $I$ or $P$ ) for financial profile $i$, the CPT valuation function is given by

$$
v\left(x_{i}^{j}\right)= \begin{cases}\left(x_{i}^{j}-r_{i}\right)^{\alpha} & \text { if } x_{i}^{j}-r_{i} \geq 0 \\ -\lambda\left|x_{i}^{j}-r_{i}\right|^{\beta} & \text { if } x_{i}^{j}-r_{i}<0\end{cases}
$$

where $\alpha$ and $\beta$ control the curvature for gains and losses, respectively, $\lambda$ is a loss aversion parameter, and $r_{i}$ is the reference point for profile $i$. Values of $x_{i}^{j}$ greater than $r_{i}$ are viewed as gains and values less than $r_{i}$ are viewed as losses. For all models, we assume $\alpha=\beta$ as recommended by Nilsson, Rieskamp, and Wagenmakers (2011).

In the first version of CPT we consider, the reference point is set at zero $\left(r_{i}=0\right.$ for all $\left.i\right)$. In the second version of CPT, the reference point is determined from the asset growth rates in the prediction task:

$$
r_{i}=g r_{A_{i}} * \frac{A_{i}}{2}
$$

where $A_{i}$ is the value of assets in profile $i$ and $g r_{A_{i}}$ is the median growth rate for asset $A_{i}$ from the prediction data. ${ }^{1}$ Note that if $g r_{A_{i}}=.02$, then $r_{i}$ is the value of the annual interest earned in the interest-based savings account. In this case, $\left(x_{i}^{I}-r_{i}\right)=0$, and the interest-based savings account appears as a gain of nothing. In the "Modeling Intuition and Additional Results" section below, we provide a more thorough analysis of how choices are related to specific values of the reference point.

In the third version of CPT, we flip the sign of $g r_{A_{i}}$ so that it is negative and then calculate reference points in the same manner as version two. The main reason for including this version of the model is that it allows us to compare the growth rate model with an alternative model that also includes a non-zero reference point. It is possible that any model with a non-zero reference point

\footnotetext{
${ }^{1}$ We attempted the modeling using the individual level growth rates for $A_{i}$; however, the modeling was too sensitive to the noise in the individual level predictions. Note that the growth rates are calculated from predictions entered into text boxes and are very noisy (e.g., see the interquartile ranges in Figure 1).
} 
would outperform standard CPT (with a zero reference point). Including the negative growth rate model in our model comparison helps address this possibility.

One might wonder why not use the debt growth rates and/or the net worth growth rates in the calculation of the reference points. In our definition of reference points, we assume that the investment amount is scaled by some quantity (i.e., reference point $=$ scale $*$ investment). We propose that this quantity is the predicted growth rate of that investment. Since the investment is framed in terms of assets (i.e., half of one's assets), the logical choice is to use the asset growth rates. The debt and net worth growth rates do not reflect beliefs about the investment amount. Thus, we do not consider them to be good candidates for inclusion in defining the reference points.

In CPT, probabilities are transformed into decision weights according to the following functions:

$$
\begin{gathered}
w^{+}(p)=\frac{p^{\gamma}}{\left(p^{\gamma}+(1-p)^{\gamma}\right)^{1 / \gamma}} \text { for gains } \\
w^{-}(p)=\frac{p^{\delta}}{\left(p^{\delta}+(1-p)^{\delta}\right)^{1 / \delta}} \text { for losses }
\end{gathered}
$$

where $\gamma$ and $\delta$ control the curvature of the probability weighting function for gains and losses, respectively. In our investment decision task, the probability of winning the prize in the PLS account was fixed at the same value (.008) for all profiles. Since there is only a single probability used in the task (the interest-based savings account has a probability of 1), we fixed $\gamma=\delta=1$ because it is impossible to obtain meaningful estimates of the probability weighting parameters when the probabilities do not vary across problems. In the supplemental materials, we also refit the models using an estimate of the probability weighting function parameter, $\gamma$, from Wu and Gonzalez (1996).

The overall subjective value of the interest-based savings account for profile $i$ is given by

$$
V(I)=v\left(x_{i}^{I}\right)
$$

and the overall subjective value of the PLS account for profile $i$ is given by

$$
V(P)=.008 * v\left(x_{i}^{P}\right)+.992 * v(0)
$$

These psychological subjective values were transformed into choice probabilities using an exponential choice rule (Stott, 2006; Rieskamp, 2008; Glöckner \& Pachur, 2012; Scheibehenne \& Pachur, 
2015):

$$
p(I, P)=\frac{1}{1+e^{-\theta[V(I)-V(P)]}}
$$

where $\theta$ is a sensitivity parameter that controls how choice probabilities change with differences in subjective values. To accommodate the fact that $\theta$ has units that depend on the value function parameter $\alpha$, we apply the "bug fix" recommended by Stewart, Scheibehenne, and Pachur (2018) where the subjective values $V(I)$ and $V(P)$ are converted to their \$ equivalents by using the inverse value function (inverse of equation 3) before applying the exponential choice rule (see Stewart et al., 2018, for details).

The three versions of CPT were fit using hierarchical Bayesian parameter estimation, following Scheibehenne and Pachur (2015); Nilsson et al. (2011). A hierarchical model defines two types of parameters - hyperparameters that capture population level information and person-specific parameters that capture individual differences. In versions one and three of CPT (zero reference point and negative growth rate reference point), the person specific parameters are the risk-aversion parameter $\alpha_{n}$ and choice sensitivity parameter $\theta_{n}$ where $n$ indexes participants. These parameters are first transformed to the probit scale using the inverse cumulative distribution function (Scheibehenne \& Pachur, 2015; Nilsson et al., 2011). The individual probitized parameters are assumed to come from normal distributions defined by the hyperparameters, $\mu_{\alpha}, \sigma_{\alpha}, \mu_{\theta}$, and $\sigma_{\theta}$. The second version of CPT (growth rate reference point) estimated these parameters along with the loss aversion parameter $\lambda_{n}$ (where the probitized $\lambda_{n}$ is drawn from a normal distribution with hyperparameters $\mu_{\lambda}$ and $\sigma_{\lambda}$ ). Note that loss aversion is not included in the first and third models because there are no losses when the reference point is less than or equal to zero. Losses only occur when the reference point is greater than zero, which only happens in version two of the model. The priors for the hyperparameters are presented in the Supplemental Material.

Three MCMC chains were used to estimate the posterior distributions for the parameters using JAGS (Plummer et al., 2003). There were 5,000 samples in the burn-in and 10,000 samples were recorded for each chain. Chain convergence was assessed using the $\hat{R}$ statistic where values lower than 1.1 are considered satisfactory (Lee \& Wagenmakers, 2014). For all models and parameters, the $\hat{R}$ values met this criterion. For model comparison, we calculated the deviance information criterion (DIC) in JAGS (Spiegelhalter, Best, Carlin, \& Van Der Linde, 2002). This measure is a generalization of the AIC for hierarchical models where smaller values are preferred to larger val- 
ues. The DIC values for the three models are shown in Table 2. The DIC values for models one and three (zero reference point and negative growth rate reference point) are very similar. However, the DIC value for the second model (growth rate reference point), is 141 points lower than the zero reference point model, suggesting it provides a much better accounting of the data. ${ }^{2}$ The model fits (i.e., posterior predictives) for all three models are shown in Figure 3.
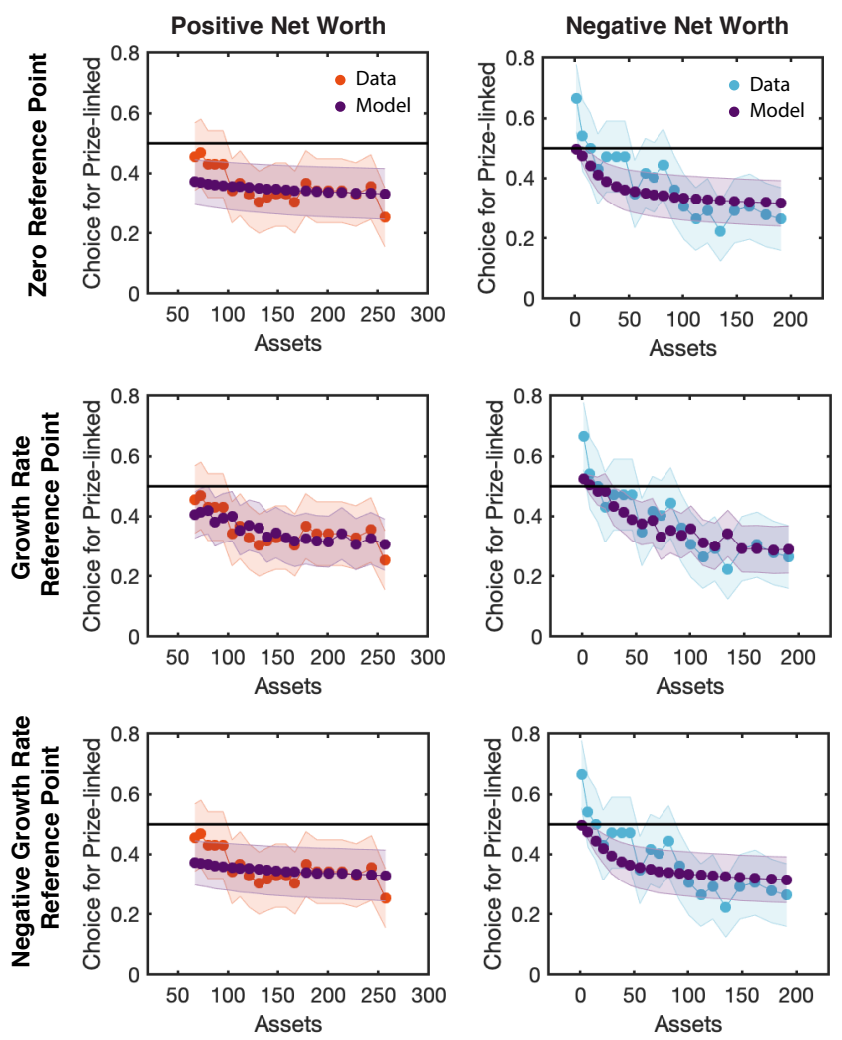

Figure 3. : Modeling results for Experiment 1 for three versions of CPT (top: zero reference point, middle: growth rate reference point, bottom: negative growth rate reference point). The panels show the posterior predictive for the model (purple) compared to the choice data (left panels are the positive net worth condition and right panels are the negative net worth condition). Error bands show $95 \%$ confidence intervals.

In addition to assessing the model fit, we also examined the posterior parameter estimates for each model. Figure 4 shows the joint posteriors for the hyperparameters for all three models. Because models one and three only had two parameters $(\alpha$ and $\theta)$, there is only a single joint posterior. Model two also included loss aversion because positive reference points can lead to situations where options appear as losses. In this case, there are three joint posteriors. As shown

\footnotetext{
${ }^{2}$ A DIC difference of 10 provides strong support for a model.
} 
Table 2:: DIC values for Cumulative Prospect Theory Models

\begin{tabular}{ccc}
\hline Model Variant & Experiment 1 & Experiment 2 \\
\hline Zero reference point & 2100 & 1545 \\
Growth rate reference point & 1959 & 1430 \\
Negative growth rate reference point & 2106 & 1536 \\
\hline
\end{tabular}

in the figure, models one and three have difficulty estimating both $\alpha$ and $\theta$ as seen by the broad posteriors that hit the lower bound on $\alpha$ (i.e., the lower bound for risk aversion is zero). ${ }^{3}$ This suggests that these models might be misspecified. Using the growth rate as a reference point (model two) and adding loss aversion cleans up the parameter estimates and leads to more tightly estimated joint posteriors. In addition, it leads to a higher estimated value of risk-aversion (posterior mean of $\alpha=0.59$ ), which more closely matches what has been observed in other risky decision-making tasks (e.g., Tversky \& Kahneman, 1992, found $\alpha=.88$ ).

We note that the value of the loss aversion parameter, $\lambda$, is higher than that observed by Tversky and Kahneman (1992). However, recent methodological work on fitting prospect theory has defined the feasible range of $\lambda$ to be less than 10 (Nilsson et al., 2011; Broomell \& Bhatia, 2014). Thus, while our estimate is high, it remains in the feasible range. Additionally, we refit the growth rate reference point model with $\lambda$ fixed at 2.25 , the value found by Tversky and Kahneman (1992). Even with a fixed value of $\lambda$, the growth rate reference point model still provided the best fit to the data (see supplemental materials for additional details).

The above results show that the growth rate reference point model is clearly superior to the other two model variants in accounting for choices in our task. However, it is unclear if this result is being driven by the specific values of the reference points (i.e., the specific growth rates) or simply by the fact that the reference points are positive, allowing for loss aversion, as opposed to being zero or negative (see supplemental material for additional analyses of the negative growth rate model). To examine this question, we fit a fourth version of CPT where the reference points were randomly drawn from the range of growth rates found in the prediction task. That is, we randomly selected 40 reference points ( 20 for the positive profiles and 20 for the negative profiles) in the range [0.0117, 0.2750], where the endpoints of the range are the minimum and maximum of the median growth

\footnotetext{
${ }^{3}$ CPT parameters are often difficult to estimate (Broomell \& Bhatia, 2014).
} 

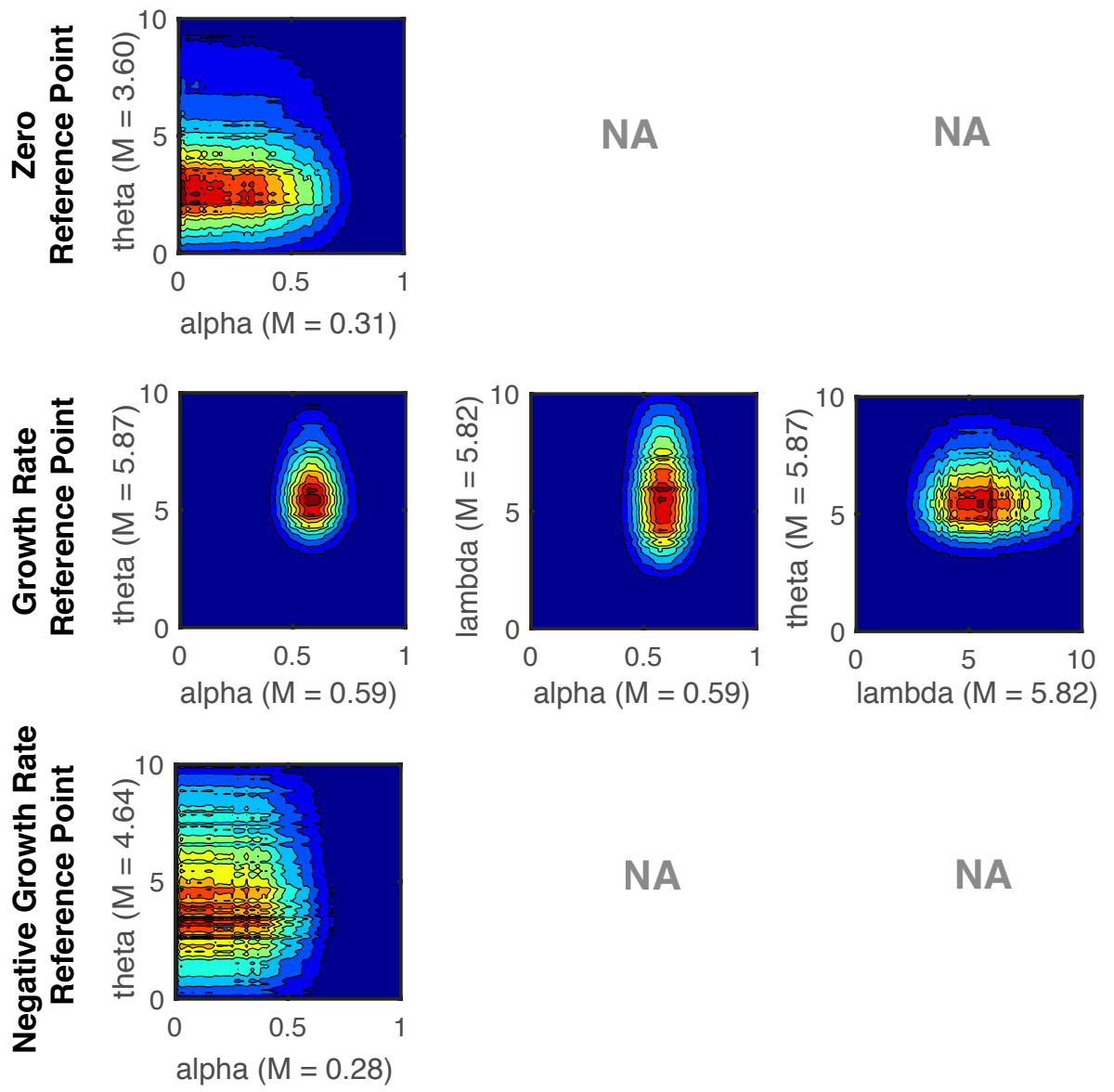

NA

NA

Figure 4. : The joint posteriors (and mean values) for the hyperparameters estimated for Experiment 1 for three versions of CPT (top: zero reference point, middle: growth rate reference point, bottom: negative growth rate reference point).

rates from the prediction task. All model fitting procedures were the same as before. The DIC for this model with randomly generated positive reference points was 2113 , which is similar to the DIC values of the zero and negative growth rate reference point models and 154 points worse than the growth rate reference point model. We also fit a version of the random positive reference point model where the growth rates from the prediction task were shuffled so that they were mismatched with the profiles in the choice task. This model produced similar results with a DIC value of 2107. Thus, it is not the case that a model with any positively valued reference points yields a better fit. These results suggest that it is the structure in the growth rates themselves that lead to improved model performance. Note that we provide a detailed analysis of how choices are related to different positive reference points in the "Modeling Intuition and Additional Results" section below. 


\section{Experiment 2}

Experiment 1 found no influence of net worth on saving decisions. However, in that experiment there were only two net worth values $(\$ 66,000$ and $-\$ 66,000)$. In Experiment 2, we further examine whether net worth influences choices by using a new set of profiles where net worth is varied. This experiment serves as an additional test of the hypothesis that beliefs act as reference points in financial decisions; thus, serving as a conceptual replication of Experiment 1.

\section{Methods}

Participants. 196 Amazon Mechanical Turk participants completed the experiment in exchange for $\$ 1.00$ in February 2019. We set a sample size of approximately 100 participants per condition and the experiment had two between-subjects conditions.

Materials. The stimuli consisted of 40 financial profiles made up of 20 profiles with small assets and 20 profiles with large assets. The type of profile (small asset versus large asset) was a between-subjects condition. The small asset profiles were generated by using the 20 debt amounts from the positive net worth profiles from Experiment 1 and randomly selecting 20 asset amounts between $\$ 73,000$ and $\$ 83,000$ so that there were 10 positive net worth and 10 negative net worth profiles. The large asset profiles were generated by using the 20 debt amounts from the negative net worth profiles from Experiment 1 and randomly selecting 20 asset amounts between $\$ 140,000$ and $\$ 150,000$ so that 10 profiles had positive net worth and 10 had negative net worth. A complete list of the profiles used in this experiment are in the Supplemental Material. Similar to Experiment 1, the 40 profiles were used in two tasks: a prediction task and a investment decision task. In the investment task, the prize amounts offered by the PLS account were selected so that the expected value of this account was the same as the interest earned from the interest-based savings account offering $2 \%$ annually.

Procedure. At the start of the experiment, participants were randomly assigned to either the small asset or large asset condition. Participants completed both the prediction and investment decision tasks using the 20 profiles for their condition. The order of the two tasks was randomized (half of participants completed the prediction task before the investment decision task and vice versa) with a distractor task between the two. Similar to Experiment 1, all of the questions were 
framed using first person. The instructions and format of the prediction and investment decision tasks were identical to Experiment 1.

Results

Behavioral Results. For the data analyses below, we applied the same exclusion criteria as before, excluding participants with 10 out of 40 responses that were three scaled median absolute deviations away from the median response for a given question. This removed 43 participants, leaving 153 for the data analyses.

As in Experiment 1, we conducted four Wilcoxon signed rank tests (one for each condition: small/large $\times$ assets/debt) to determine whether participants' future predictions were generally larger or smaller than the given present values. Participants' predictions for assets were generally larger than present values for profiles with both small $(Z=14.09, p<.001)$ and large $(Z=14.31$, $\mathrm{p}<.001)$ assets. Across the 20 asset questions in each condition, the average difference between predictions and present values was greater than zero for most participants $(68.0 \%$ of participants in the small asset condition and $73.3 \%$ of participants in the large asset condition). Participants' predictions for debts were generally smaller than present values for profiles with both small $(\mathrm{Z}=$ $-27.49, \mathrm{p}<.001)$ and large $(\mathrm{Z}=-22.49, \mathrm{p}<.001)$ assets. Across the 20 debt questions in each condition, the average difference between predictions and present values was less than zero for most participants (85.9\% of participants in the small asset condition and $77.3 \%$ of participants in the large asset condition).

To further investigate participants' predictions, we calculated the growth rate for assets and debts for each profile, similar to Experiment 1. We then fit a three parameter exponential curve to the median growth rates (i.e., median growth rate $=a+b e^{r x}$ where $x$ is the present net worth of the profile) for each of the four sets of predictions (small, large $\times$ assets, debt). As seen in Figure 5, assets in both the small and large conditions are generally predicted to grow for all values of net worth (i.e., data and fitted curve are above zero). This is supported by positive parameter estimates for $a$ and $b$ (see Table 3 for parameter estimates). Debts in both the small and large conditions are generally predicted to shrink for all values of net worth (i.e., data and fitted curve are below zero). This is supported by negative parameter estimates for $a$ and $b$. Participants' predictions were generally more extreme for larger net worth profiles (supported by positive $r$ values). 

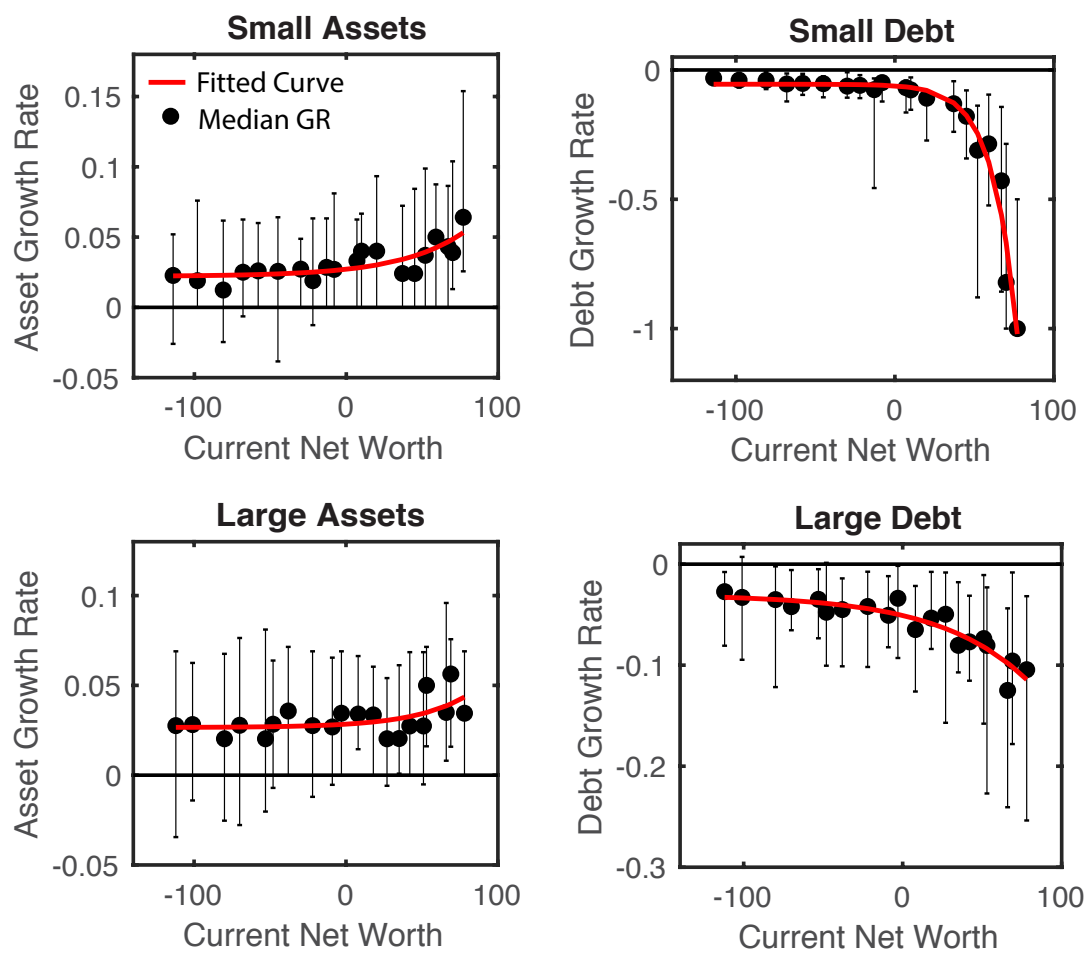

Figure 5. : Growth rates calculated from prediction data in Experiment 2 for assets and debts in the small asset/debt and large asset/debt conditions. The $\mathrm{x}$-axis is the given net worth. The black points are the median predictions and the error bars represent the 0.25 and 0.75 quantiles. The red curve is the best fitting exponential function to the median growth rates.

Table 3:: Parameter Estimates for Exponential fit to Growth Rates from Experiment 2. 95\% confidence intervals are in parentheses.

\begin{tabular}{ccccc}
\hline Profile & $\mathrm{a}$ & $\mathrm{b}$ & $\mathrm{r}$ & $R^{2}$ \\
\hline Small Assets & $0.022(0.014,0.030)$ & $0.005(-0.005,0.015)$ & $0.024(-0.001,0.048)$ & 0.65 \\
Small Debt & $-0.055(-0.089,-0.021)$ & $-0.007(-0.014,0.001)$ & $0.065(0.050,0.080)$ & 0.96 \\
Large Assets & $0.027(0.019,0.034)$ & $0.002(-0.006,0.009)$ & $0.028(-0.025,0.082)$ & 0.29 \\
Large Debt & $-0.030(-0.046,-0.015)$ & $-0.021(-0.039,-0.002)$ & $0.018(0.007,0.029)$ & 0.87 \\
\hline
\end{tabular}

Next, we examined people's choices on the investment decision task. There were no differences in choice behavior by task order (i.e., whether participants performed the investment decision task before or after the prediction task), $\mathrm{t}(74)=-0.82, \mathrm{p}=0.417$ for the small asset condition and $\mathrm{t}(67)=0.61, \mathrm{p}=0.547$ for the large asset condition. Similar to Experiment 1, people were typically risk averse (see Figure 2 right panel), preferring the interest-based savings account to the PLS 
account (mean choice proportion for the PLS account was 0.36 for the small profiles and 0.24 for the large profiles). Similar to Experiment 1, we fit a GLMM to the choice proportions for the PLS account with four fixed effects predictors, asset amount (in dollars), net worth (in dollars), and their interaction plus a fixed intercept. As in Experiment 1, we used a probit link function and allowed for by-item (i.e., profile) random intercepts. Results showed that choice proportions for the PLS account differed significantly by asset amount $(\beta=-0.005, \mathrm{t}(36)=-6.92, \mathrm{p}<0.001,95 \%$ CI [0.007, -0.004]), showing that the PLS account was more often preferred when assets were small as compared to large (consistent with Experiment 1). There was a marginal effect of net worth $(\beta=$ $-0.003, \mathrm{t}(36)=-1.78, \mathrm{p}=0.084,95 \% \mathrm{CI}[-0.006,0.0004])$ and the interaction between asset amount and net worth was not significant $(\beta=.00001, \mathrm{t}(36)=1.13, \mathrm{p}=.267,95 \% \mathrm{CI}[-.00001, .00004])$.

Modeling Results. To investigate the relationship between predicted growth rates and choices on the investment decision task, we fit the same three versions of CPT as used in Experiment 1. All model assumptions and parameter estimation methods were identical to Experiment 1.

As shown in Table 2, the DIC values for models one and three (zero reference point and negative growth rate reference point) are similar and worse than model two (growth rate reference point). The DIC value for the second model is 115 points lower than the zero reference point model and 106 points lower than the negative growth rate reference point model, suggesting it provides a much better accounting of the data. The model fits (i.e., posterior predictives) for all three models are shown in Figure 6.

Figure 7 shows the joint posteriors for the hyperparameters for all three models. Similar to Experiment 1, we see that models one and three have difficulty estimating $\theta$ as seen by the broad joint posteriors. On the other hand, model two has more tightly estimated joint posteriors, suggesting that the inclusion of the growth rate reference point and loss aversion leads to better parameter estimation.

The above results show that the growth rate reference point model provides a significantly better accounting of the data than the other two model variants, consistent with Experiment 1. To further test whether this result is a consequence of the reference points simply being positive as opposed to zero or negative, we fit a fourth version of CPT where the reference points were randomly drawn from the range of growth rates found in the prediction task ([0.0123, 0.0641]). The DIC value for this model was 1560 , which is worse than the DIC values of the three original model 

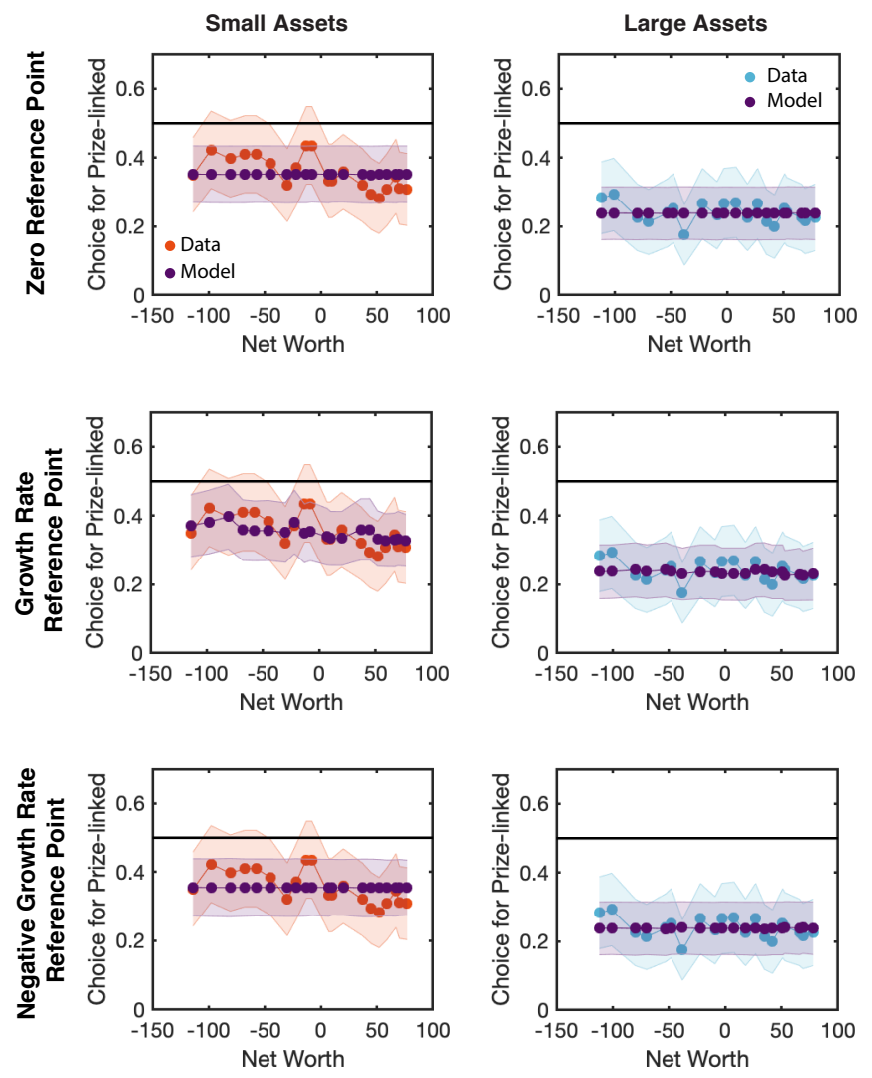

Figure 6. : Modeling results for Experiment 2 for three versions of CPT (top: zero reference point, middle: growth rate reference point, bottom: negative growth rate reference point). The panels show the posterior predictive for the model (purple) compared to the choice data (left panels are the small asset/debt condition and right panels are the large asset/debt condition). Error bands show 95\% confidence intervals.

variants. We also tried generating random reference points by shuffling the growth rates from the prediction task. This model produced identical results, with a DIC value of 1560. As in Experiment 1 , these results suggest that the improved performance of the growth rate reference point model is not simply due to it having positive reference points, rather the structure in the growth rates matters.

Modeling Intuition and Additional Results. Modeling results from both Experiments 1 and 2 show strong support for the growth rate reference point model. An important question is why does this model outperform the others. To answer this question, we performed a simulation study where we generated predictions from the model for 80 different financial profiles (the 40 profiles from Experiment 1 and the 40 profiles from Experiment 2), varying the growth rate reference point from 0 to 0.3 . The top panel in Figure 8 shows the model simulation results averaged over the 80 

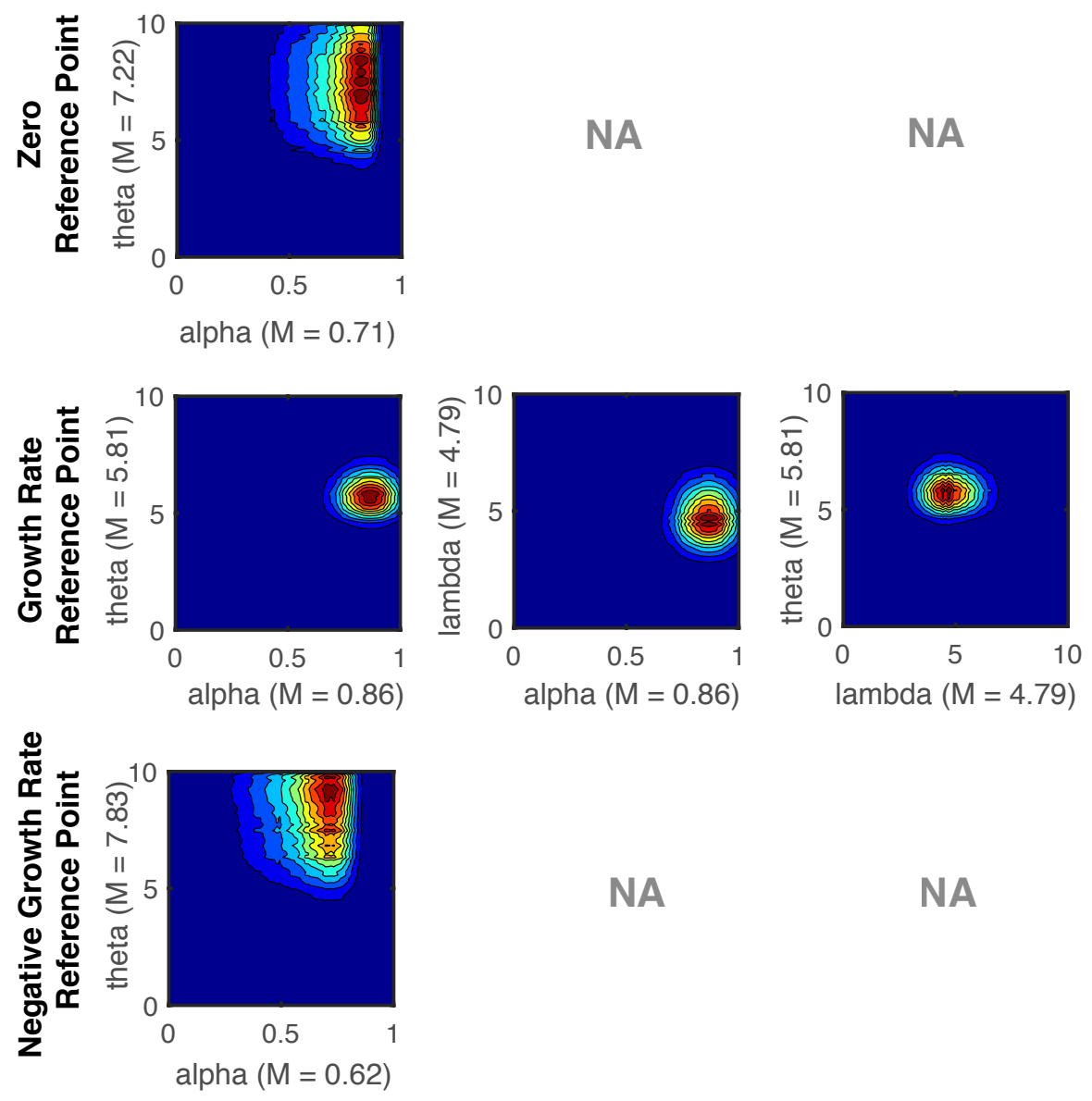

NA

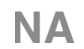

Figure 7. : The joint posteriors (and mean values) for the hyperparameters estimated for Experiment 2 for three versions of CPT (top: zero reference point, middle: growth rate reference point, bottom: negative growth rate reference point).

profiles for different values of the risk-aversion parameter $\alpha$. As shown in the figure, the model predicts that choices for the prize-linked savings account decrease for growth rates between 0 and .02 and then increase for growth rates larger than .02 . When the growth rate is 0 , this corresponds to the "zero reference point" model that we fit. In this case, choice proportion is entirely driven by the risk-aversion parameter. As this parameter approaches $\alpha=1$, the choice proportion approaches 0.5 because the two investment options had equal expected value.

When the growth rate is between 0 and .02 , choice proportion for the prized-linked account drops off sharply. In both experiments, the interest rate for the interested-based savings account was $2 \%$, thus reference points less than $2 \%$ make the interested-based account look like a sure gain. In 
this case, the interested-based account is preferred since it is a safe gain, as compared to the prizedlinked account which is a risky option offering both a gain and potential loss (when the reference point is positive, the $\$ 0$ outcome in the prized-linked account is a loss).

When the growth rate is greater than .02 , the choice proportion for the prized-linked account increases. This is because the interest-based account now becomes a sure loss. In this case, the decision-maker is faced with the choice between a small sure loss and a mixed gamble offering a large gain and loss. As shown in the figure, choice proportion for reference points greater than .02 depend strongly on the risk-aversion parameter.

In the bottom panel of Figure 8, we plot the median growth rates for all 80 profiles used in Experiments 1 and 2 against the choice proportion for the prized-linked account in those profiles. As shown in the figure, almost all of the growth rates are greater than .02. Importantly, we see that as growth rates increase, choice proportions also tend to increase. This is in line with the model simulation results shown in the top panel. Thus, the growth rate reference point model provides the best account of the data because people's choices for the prize-linked account are related to their predicted growth rates in a similar way as the model.

\section{Experiment 3}

Experiments 1 and 2 found that people's beliefs about the future were optimistic. This optimism might have resulted from asking people to imagine that the profiles described their financial situation, as opposed to another person's situation. People tend to be more optimistic for themselves than for others (Weinstein, 1980; Weinstein \& Lachendro, 1982; Shepperd et al., 2013). In Experiment 3, we repeat the prediction task from Experiment 1, but change the framing from first person to third person. We also compare the results to real world data to examine whether people's judgments are biased or not.

\section{Methods}

Participants. 199 Amazon Mechanical Turk participants completed the experiment in exchange for $\$ 1.00$ in October 2018. We set a sample size of 100 participants per condition and the experiment had two between-subjects conditions. 

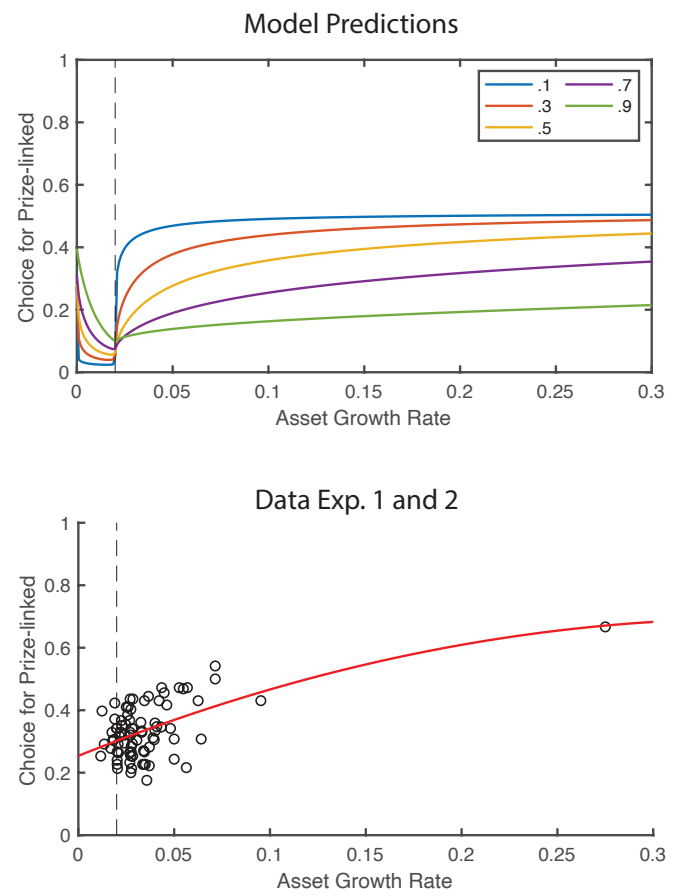

Figure 8. : Top panel: Model simulation results for 80 different financial profiles (the 40 profiles from Experiment 1 and the 40 profiles from Experiment 2) varying the growth rate reference point from 0 to 0.3 . The results were averaged over the 80 profiles for different values of the risk-aversion parameter $\alpha$ (different colored lines in the figure). For these simulations, $\lambda=3$ and $\theta=1$. Results were similar for other values of $\lambda$ and $\theta$. Bottom panel: growth rates for all 80 profiles used in Experiments 2 and 3 plotted against the choice proportion for the prized-linked account in those profiles. The red line is the best fit degree 2 polynomial. The dotted lines in both panels shows growth rate equal to 0.02 (the interest rate for the interest-based savings account).

Materials. The stimuli consisted of the same 40 financial profiles (20 positive net worth and 20 negative net worth profiles) used in Experiment 1 (see the Supplemental Material for a list of the profiles). However, participants were asked to imagine that the profiles described a hypothetical other person, rather than themselves as in Experiments 1 and 2.

Procedure. At the start of the experiment, participants were randomly assigned to either the positive or negative net worth condition. Participants were instructed that on each trial they would see an individual's current financial profile (described as assets and debt) and that their task was to predict the future value of the individual's assets and debts one year from now. Participants were also told that they would see a different person on each question and to assume that all people had 
steady jobs and did not anticipate any unusual expenses in the upcoming year. To emphasize that each question was about a different individual, the name of the individual was provided on each question. Names were in the format "Mr. X" where "X" was a single letter. An example question is provided below:

Mr. X has $\$ 67,000$ in assets, and $\$ 1,000$ in debt.

In 1 year, what do you estimate Mr. X's assets will be?

In 1 year, what do you estimate Mr. X's debt will be?

The order of the profiles was fully randomized.

Results

Behavioral Results. For the data analyses below, we applied the same exclusion criteria as in Experiments 1 and 2, excluding participants with at least 10 out of 40 responses that were three scaled median absolute deviations away from the median response for a given question. This removed 45 participants, leaving 154 for the data analyses.

First, we conducted four Wilcoxon signed rank tests (one for each condition: positive/negative net worth $\times$ assets/debt) to determine whether participants' predictions about the future were generally larger or smaller than the given present values. Participants' predictions for assets were generally larger than present values for both positive $(\mathrm{Z}=13.84, \mathrm{p}<.001)$ and negative $(\mathrm{Z}=17.02, \mathrm{p}<.001)$ net worth profiles. Across the 20 asset questions in each condition, the average difference between predictions and present values was greater than zero for most participants $(75.2 \%$ of participants in the positive net worth condition and $73.2 \%$ of participants in the negative net worth condition). Participants' predictions for debts were generally smaller than present values for both positive $(Z=-9.60, p<.001)$ and negative $(Z=-6.32, p<.001)$ net worth profiles. Across the 20 debt questions in each condition, the average difference between predictions and present values was less than zero for most participants $(60.4 \%$ of participants in the positive net worth condition and $57.7 \%$ of participants in the negative net worth condition).

To further investigate participants' predictions, we calculated the growth rate for assets and debts for each profile, similar to Experiments 1 and 2. We then fit a three parameter exponential curve (see equation 2) to the median growth rates for each of the four sets of predictions (positive, 
negative $\times$ assets, debt). As seen in Figure 9, assets in both positive and negative net worth conditions are generally predicted to grow (i.e., data and fitted curve are above zero). This is supported by positive parameter estimates for $a$ and $b$ (see Table 4 for parameter estimates). Debts in the positive net worth condition are generally predicted to shrink (i.e., data and fitted curve are below zero). This is supported by negative parameter estimates for $a$ and $b$. Predictions for debts in the negative net worth condition depend on the size of the profile. For profiles with small assets and small debts, debts are predicted to grow, unlike Experiments 1 and 2 where they were predicted to shrink. This difference is likely due to the change in the framing of the question from first person (Experiments 1 and 2) to third person (Experiment 3), suggesting that the optimistic judgments we found in Experiment 1 might be due in part to self / other differences. However, this is the only systematic difference between the judgments across the three experiments. Importantly, for negative profiles with large assets and large debts, debts are predicted to shrink, consistent with Experiments 1 and 2. In all cases, participants predicted more extreme changes for small assets and small debts (supported by negative $r$ values in all cases). In sum, while there are some minor differences in the judgments across experiments, results from all three experiments show that people are optimistic about the future.

Table 4:: Parameter Estimates for Exponential fit to Growth Rates from Experiment 3. 95\% confidence intervals are in parentheses.

\begin{tabular}{ccccc}
\hline Profile & $\mathrm{a}$ & $\mathrm{b}$ & $\mathrm{r}$ & $R^{2}$ \\
\hline Positive Assets & $0.018(-0.003,0.038)$ & $0.091(-0.020,0.201)$ & $-0.014(-0.035,0.007)$ & 0.57 \\
Positive Debt & $-0.037(-0.056,-0.018)$ & $-0.899(-1.009,-0.789)$ & $-0.171(-0.214,-0.128)$ & 0.96 \\
Negative Assets & $0.043(0.032,0.053)$ & $0.577(0.507,0.648)$ & $-0.237(-0.299,-0.174)$ & 0.97 \\
Negative Debt & $-0.016(-0.021,-0.011)$ & $4.508(-8.277,17.290)$ & $-0.065(-0.106,-0.025)$ & 0.78 \\
\hline
\end{tabular}

Panel Study of Income Dynamics (PSID) Results. Results from all three experiments show that participants are generally optimistic about the future. In particular, in Experiment 3, they predict that assets will grow over the course of one year for both individuals with positive and individuals with negative net worth. They also predict that debts will shrink for individuals with positive net worth and for individuals with negative net worth who have large assets/debt. The only situation where participants have a pessimistic view of the future is when they consider debts for individuals 

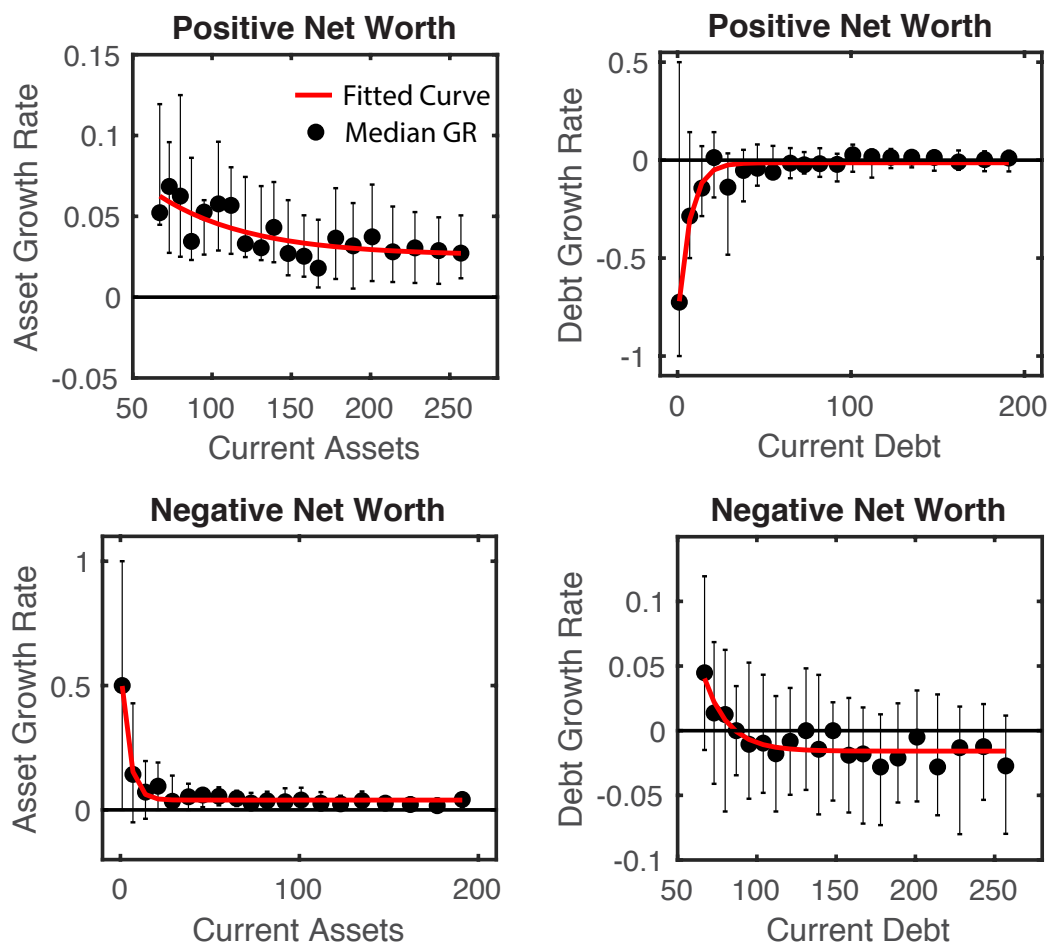

Figure 9. : Growth rates calculated from prediction data in Experiment 3 for assets and debts in the positive and negative net worth conditions. The $\mathrm{x}$-axis is the given value of assets/debts. The black points are the median predictions and the error bars represent the 0.25 and 0.75 quantiles. The red curve is the best fitting exponential function to the median growth rates.

with negative net worth who have small assets/debt.

An important question is whether people's predictions are consistent with how assets and debts actually change in the real world. To help address this question, we examined changes in individuals' assets and debts using data from the Panel Study of Income Dynamics (PSID). The PSID is a longitudinal panel survey of American families measuring a variety of factors including income, wealth, employment, heath, and many other topics. In recent years, the PSID has conducted their main interview every two years. Using data collected in 2017 and 2019, we calculated the growth rates (using equation 1) of assets and debts for individuals over this two year period (note that Experiments 1-3 were conducted in 2018 and 2019). For this analysis, we only included individuals who were designated as "heads" of households, did not move homes between 2017 and 2019, were employed at the time of the interview in both years, and had no changes to their household composition (e.g., no births, deaths, divorces, or marriages). These exclusions were intended to reflect characteristics of a household described to participants in all three experiments. The PSID has seven 
main questions relating to assets (asking people to report the value of business/farm assets, checking and savings accounts, stocks, vehicles, annuity/ IRA, other real estate assets, and other assets). The PSID has eight main questions relating to debt (querying people's debts related to business/farm, credit cards, student loans, medical debt, legal debt, family loans, other real estate, and other debt). In addition, we included home equity (value of home minus mortgage) in our calculations. We restricted the analysis to individuals with assets/debts less than $\$ 300,000$, since the maximum value of assets / debt in the profiles used in our experiments was $\$ 257,000$. This left us with a final sample of 2,121 responses.

From 2017 to 2019, 57\% of individuals with positive net worth increased their assets (median growth rate $=0.111$ ) and $64 \%$ of individuals with negative net worth increased their assets (median growth rate $=0.422$ ). During this two year period, $62 \%$ of individuals with positive net worth decreased their debts (median growth rate $=-0.267$ ) and $60 \%$ of individuals with negative net worth decreased their debts (median growth rate $=-0.100$ ). Thus, for the majority of individuals in this analysis, assets grew and debts shrunk. As shown in Figure 10, there is considerable variation in asset and debt growth rates across individuals, but the median growth rates are very similar to the growth rates calculated from the prediction data in Experiment 3. In the figure, the grey points represent growth rates for individuals in the PSID data with assets/debts less than $\$ 300,000$. The blue lines are the median growth rates calculated from this data. The orange lines are the median two year growth rates calculated from the prediction data in Experiment 3 (error bands show the .5 and .95 quantiles).

In sum, people's beliefs about the future value of assets and debts are fairly consistent with PSID results (as seen by the overlap of the orange error bands in Figure 10 with the blue lines). Participants in Experiment 3 predicted that assets would generally increase and debts would generally shrink (except for small debts in negative net worth). For the majority of the individuals in the PSID analysis, this is true. We note that the individuals included in our analysis of the PSID data were generally in very stable situations (e.g., heads of households that were employed, had no changes to family composition, and did not move). Thus, the trends we see in the data may not reflect the more general population, which would include individuals in less stable situations. However, these trends are consistent with participants' optimistic predictions from all three experiments, in which participants were specifically instructed to imagine stable financial situations. Thus, we conclude 
that - while optimistic - there is no evidence that people's predictions in our experiments are biased.
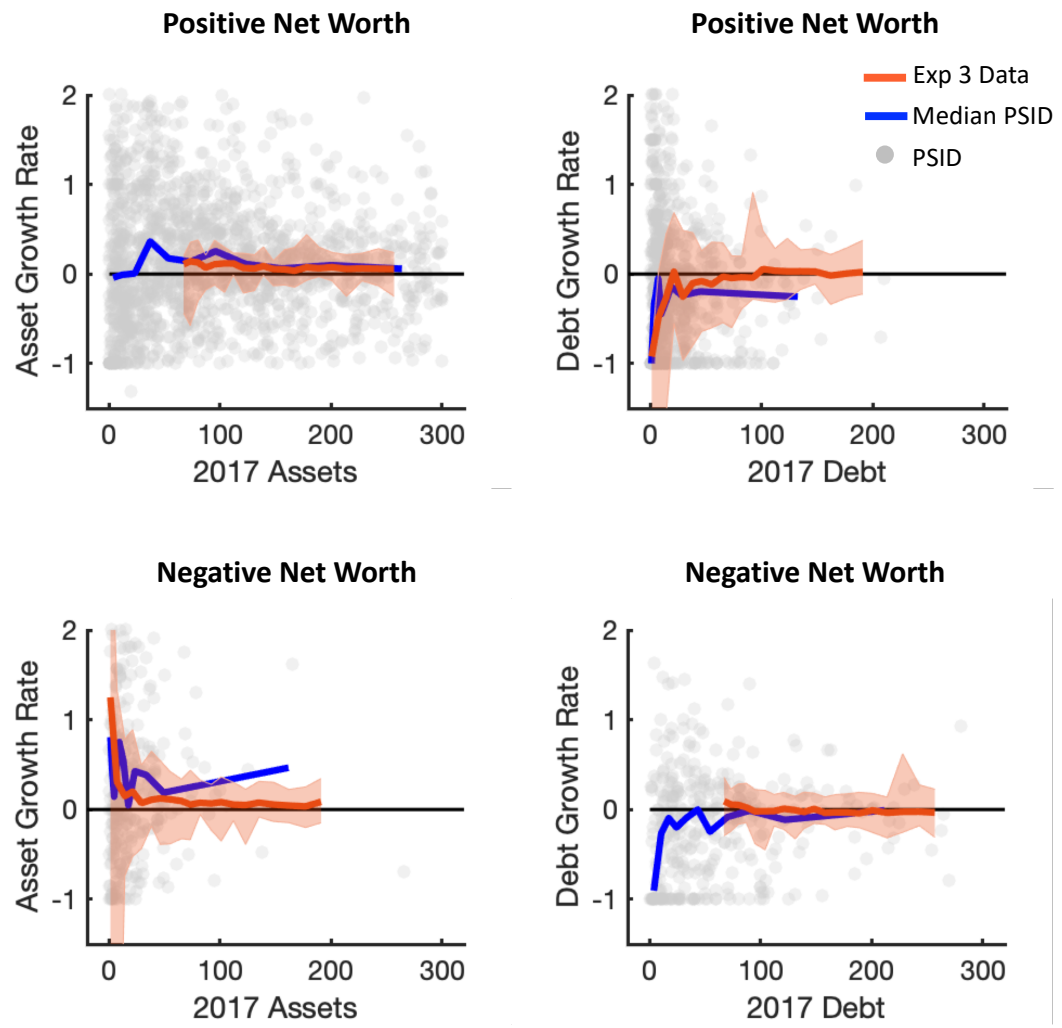

Figure 10. : Growth rates calculated from 2017 and 2019 PSID data for assets and debts for families with positive and negative net worth. The $\mathrm{x}$-axis is the value of assets/debts in 2017. The gray dots represent families with assets and debts between $\$ 0$ and $\$ 300,000$ and unrestricted net worth. The orange line is the median two year growth rate calculated from Experiment 3 and the shaded error band shows the .5 and .95 quantiles. The blue line is the median of the PSID growth rates for each of 10 quantiles calculated on the asset/debt amounts in 2017. These median values are plotted at the midpoint of each quantile.

\section{Survey of Beliefs and Stock Market Decisions}

Results from Experiments 1 and 2 show that people's beliefs about their future wealth serve as reference points when making financial decisions. In those experiments, computational modeling was used to test and compare different reference point theories. While the modeling results are quite conclusive, there are several limitations to those studies. First, they rely on interpretations of a specific cognitive model, Prospect Theory. Second, both experiments use the same task involving decisions between a traditional savings account and a PLS account. Thus, it is unknown if the results 
would generalize to other financial decisions. Using data from a large-scale cross-sectional survey, we provide supporting evidence for belief-based reference points in the context of decisions about the US stock market. Finally, presenting participants with a series of wealth profiles had the benefit of allowing for tight experimental control. However, participants may have had difficulty imagining the asset and debt profiles that were presented to them. In the current survey, participants instead make predictions about their own wealth.

In the survey, we ask participants to make predictions about the growth rate of their assets and debts as well as an investment decision regarding the US stock market. Our main interest is whether people's stated growth rates predict their investment decisions. The survey was run in Summer 2020, during the COVID-19 pandemic, because we anticipated large heterogeneity in people's beliefs about their future wealth due to the co-occurring economic crisis. Such heterogeneity is beneficial for our purposes, as we need a wide range of future beliefs to test our theory. In Experiments 1, 2, and 3, which were run before the COVID-19 health crisis in the US, we observed that people's future beliefs were overwhelmingly optimistic. Thus, the economic crisis associated with the COVID-19 pandemic provided a unique opportunity to examine beliefs about future wealth and investment decisions.

\section{Methods}

Participants. We targeted a nationally representative sample of participants using Lucid (Coppock \& McClellan, 2019) in three separate cross-sectional waves with a total of 4,606 participants completing the survey. Waves were started on May 19, $2020(n=1560)$, May 27, 2020 $(n=1825)$, and June 2, $2020(n=1221)$. Each wave was run for one week and was then closed before the start of the next wave. We targeted 2,000 participants per wave, with a minimum sample size of 1000. Sample sizes for the waves reported here are below the targeted 2,000 participants because we did not reach that number within a week; however, the sample sizes are above the minimum targeted sample size. The rule for determining sample size (i.e., three waves of data collection with one-week in each wave) was predetermined before running the study, and we did not analyze data until all data had been collected. Participants ranged in age from 18-90 $(M=45), 36 \%$ were male, with an average income of approximately $\$ 57,000 .^{4}$ This study was approved by the Institutional

\footnotetext{
${ }^{4}$ We note that the percentage of males in the survey is lower than the national percentage. While Lucid targets a nationally representative sample, it does not guarantee an exact match.
} 
Review Board at a Midwestern university.

Materials and Procedure. The questions analyzed for this study were part of a larger survey examining the beliefs and behavior of individuals during the COVID-19 pandemic. After entering the survey and providing consent, participants answered approximately 50 questions. These questions fell into several different categories including: psychological characteristics (e.g., positive and negative affect), COVID-19 perceptions and behaviors (e.g., predictions about future spread), employment and financial impacts (e.g., predictions of future wealth), investment beliefs and behaviors (e.g., predictions about the S\&P 500's average returns), consumer activity (e.g., charitable giving), and demographics.

We focus our analysis on several key questions. To measure people's beliefs about their future wealth, we first told people to "Think about your assets and debts at the beginning of January 2020 (prior to the COVID-19 outbreak in the US). Relative to that, what do you predict that your assets and debts will be in January 2021?" After reading these instructions, participants reported the predicted change in their assets and debts on a 13 point scale: $1=$ "decrease by more than $5 \%$ ", 2 = "decrease between 4-5\%", 3 = "decrease between $3-4 \%$ ", 4 = "decrease between $2-3 \%$ ", $5=$ "decrease between 1-2\%", $6=$ "decrease between $0-1 \%$ ", $7=$ "no change $(0 \%)$ ", $8=$ "increase between 0-1\%", 9 = "increase between 1-2\%", $10=$ "increase between 2-3\%", 11 = "increase between 3-4\%", 12 = "increase between 4-5\%", 13 = "increase by more than 5\%". They made separate predictions for assets and debts, similar to Experiments 1-3. Participants were also provided instructions on how to interpret a percentage change in assets / debts: "For example, if your assets in January 2020 were about $\$ 10,000$ and you believe they will increase by $1 \%$, this means you predict your assets will be $\$ 10,100$ in January 2021.”

Participants also completed several questions related to investing in the US stock market. Our main question of interest involved participants allocating money between a US stock market index fund and a bond. For this question, participants were told "Imagine that you received $\$ 1,000$ that you did not need to use right away. How much of this money would you invest in the US stock market (e.g., an index fund representing a broad stock market index) versus a bond earning $2 \%$ with certainty?" After reading these instructions, participants entered one amount for the US stock market index fund and another amount for the bond earning $2 \%$ per year. The two amounts were required to add up to $\$ 1,000$. In addition to this question, we also asked participants whether they 
currently held any investments (response options of 'yes', 'no', and 'not sure') and their predictions about the S\&P 500's average returns. There were two prediction questions. In the first, participants reported their estimate of what they thought the S\&P 500's average returns would be per-year over the next year. In the second, participants reported their estimate for the S\&P 500's average returns per-year over the next year 10 years. Responses on both questions were measured using a 13 point scale: 1 = "down more than 25\%", 2 = "down 21-25\%", 3 = "down 16-20\%", 4 = "down 11-15\%", 5 = "down 6-10\%", $6=$ "down 1-5\%", 7 = "0\%", 8 = "up 1-5\%", 9 = "up 6-10\%”, 10 = "up 11-15\%", $11=$ "up 16-20\%”, 12 = "up 21-25\%”, 13 = "up more than 25\%".

\section{Results}

No participants were excluded from the analyses. ${ }^{5}$ Our key hypothesis is that participants who predict that their assets will increase by more than $2 \%$ will invest a larger proportion of funds in the US stock market index as compared to individuals who predict that their assets will grow by less than $2 \%$. According to our theory, people's beliefs about their future wealth serve as reference points when making investment decisions. Thus, when people predict their assets will grow by more than $2 \%$, the bond offering $2 \%$ appears as a sure loss. In this case, individuals are faced with a decision between a sure loss and an unknown gamble (i.e., the stock market index) offering a potentially large reward and loss. On the other hand, when people predict their assets will grow by less than $2 \%$, the bond offering $2 \%$ appears as a sure gain. In this case, people are faced with a decision between a sure (small) gain and an unknown gamble (i.e., stock market index) with possible gains and losses.

To test this hypothesis, we first calculated the proportion of $\$ 1000$ allocated to the stock market index over the bond. On average, people allocated about $41 \%$ of the $\$ 1000$ to the stock market index $(\mathrm{SD}=34 \%)$. Next, we binned participants into three groups based on the predicted change in their assets: assets decrease (i.e., prediction $<0$ ), assets stay the same or increase less than $2 \%$ (i.e., $0 \leq$ prediction $<2$ ), and assets increase by $2 \%$ or more (i.e., prediction $\geq 2$ ). A total of 2170 participants $(47.1 \%)$ were in the "prediction $<0$ " group, 1822 participants $(39.6 \%)$ were in the " $0 \leq$ prediction $<2$ " group, and 614 participants (13.3\%) were in the "prediction $\geq 2$ " group. This shows that participants in our study were fairly pessimistic about their future wealth as compared

\footnotetext{
${ }^{5}$ Unlike Experiments 1-3, participants in the survey reported the predicted change in their assets and debts on a 13 point scale (not a text box). Thus, the data were much cleaner and removal of outliers was not needed.
} 
to Experiments 1-3, which were run prior to the COVID-19 pandemic in the US. For the analyses described below, this binned variable was treated as a categorical factor using dummy coding where the "prediction $<0$ " group was set as the reference level. According to our hypothesis, we should see a large difference in stock allocations between the "prediction $<0$ " group and the "prediction $\geq 2$ " group. However, we expect a much smaller difference (or no difference at all) between the "prediction $<0$ " group and the " $0 \leq$ prediction $<2$ " group.

We conducted an OLS multiple linear regression to predict the proportion of funds allocated to the stock market index with the following predictors: (1) predicted change in assets (binned as described above), (2) estimate of the S\&P 500's average returns per-year over the next year, (3) estimate of the S\&P 500's average returns per-year over the next 10 years, and (4) income. The latter three predictors were included as controls. Specifically, including controls for expectations of stock market returns allows us to test whether people's beliefs about their future wealth predict stock allocation decisions above and beyond their beliefs about how the stock market will behave in the future. If we find effects of a predicted change in assets after controlling for these stock market expectations it allow us to rule out alternative accounts such as that general optimism drives beliefs about both personal assets and the stock market. We also control for income as this is likely to influence investment decisions. The model also included an intercept, but no interaction terms.

Table 5 shows the parameter estimates for the regression model. As shown in the first row of the table, there was a small negative difference in stock allocation decisions between the "prediction $<0$ " group and the " $0 \leq$ prediction $<2$ " group. However, participants in the "prediction $\geq 2$ " group invested a larger proportion of funds in the stock market index as compared to participants in the "prediction $<0$ " group, consistent with our hypothesis. These results are also illustrated in Figure 11. We also observe that participants who predict higher returns for the S\&P 500 over the next year also invested a larger proportion of funds in the stock market index. Although, this relationship does not hold for the 10 year predictions. ${ }^{6}$ Finally, participants with higher income invested a larger proportion of funds in the stock market index.

As a robustness check, we also reran this analysis restricted to participants with current investment holdings. If participants do not currently hold investments, they may be unwilling to allocate funds to a stock market index regardless of their beliefs about their future wealth. 1638

\footnotetext{
${ }^{6}$ If the 1 year S\&P 500 predictions are not included in the model, then the 10 year predictions are significant.
} 
Table 5:: OLS multiple linear regression parameter estimates

\begin{tabular}{lllllll}
\hline Name & Estimate $(\mathrm{b})$ & $\beta$ & $\mathrm{SE}$ & $\mathrm{t}$ & $\mathrm{p}$-value & $95 \% \mathrm{CI}$ \\
\hline$[0,2)$ group $-<0$ group & -0.021 & -0.031 & .011 & -1.978 & 0.048 & {$[-0.043,-0.000]$} \\
$\geq 2$ group $-<0$ group & 0.052 & 0.052 & .016 & 3.324 & $>0.001$ & {$[0.021,0.083]$} \\
S\&P 500 1 yr est. & 0.003 & 0.092 & .001 & 5.345 & $>0.001$ & {$[0.002,0.004]$} \\
S\&P 500 10 yr est. & -0.0004 & 0.012 & .001 & 0.694 & 0.488 & {$[-0.001,0.001]$} \\
income & 0.0007 & 0.094 & .0001 & 6.398 & $>0.001$ & {$[0.000,0.001]$} \\
\hline
\end{tabular}

participants (35.6\%) reported currently holding investments whereas the remainder of participants reported either not having any investments or being unsure. All results held with the restricted sample. Consistent with the main analysis, participants in the "prediction $\geq 2$ " group invested a larger proportion of funds in the stock market index as compared to participants in the "prediction $<0$ " group $(b=0.084, t=3.486, p=0.001,95 \% \mathrm{CI}=[.037,0.131])$. There was no difference in stock allocation decisions between the "prediction $<0$ " group and the " $0 \leq$ prediction $<2$ " group (b $=0.019, \mathrm{t}=.933, \mathrm{p}=0.351,95 \% \mathrm{CI}=[-.020,0.057])$. Full details of this analysis, as well as a replication of results on alternate waves of the same survey, are in the supplemental materials.

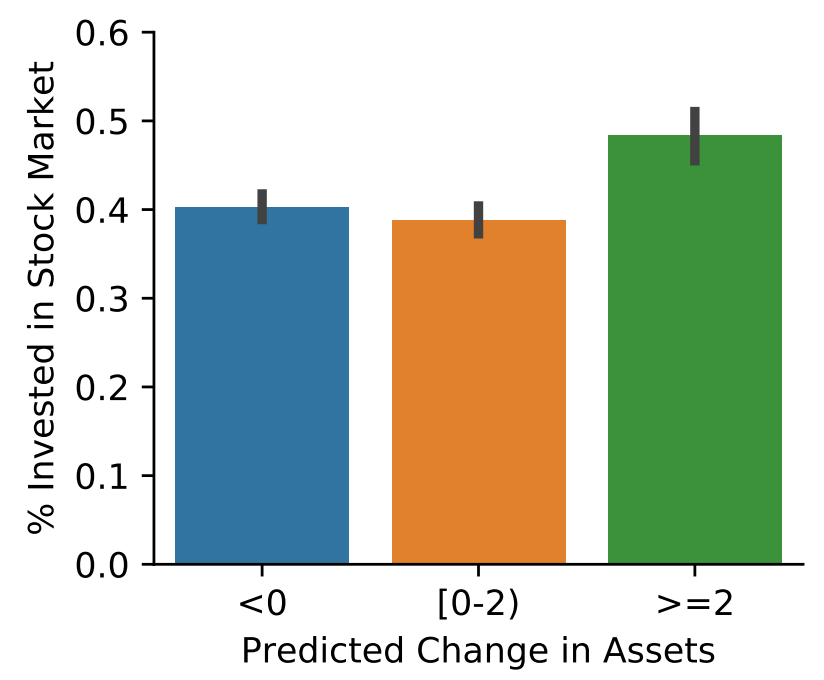

Figure 11. : Proportion of $\$ 1000$ invested in a stock market index for individuals grouped based on their predicted change in their assets. Participants were grouped into three groups based on the predicted change in their assets: assets decrease (i.e., prediction $<0$ ), assets stay the same or increase less than $2 \%$ (i.e., prediction in $[0,2)$ ), and assets increase by $2 \%$ or more (i.e., prediction $\geq 2$ ). Error bars show the $95 \%$ confidence interval. 
In sum, our results show that participants who predict that their assets will increase by more than $2 \%$ invest a larger proportion of funds in the US stock market index as compared to other participants. This result holds when controlling for beliefs about the future behavior of the stock market and income and it also holds when restricted to individuals currently holding investments. An important limitation of our survey is that the regression models do not directly test whether people's beliefs about future wealth serve as reference points when making investment decisions. Direct evidence for this hypothesis comes from the computational modeling of Experiments 1 and 2. However, the survey results are consistent with the hypothesis that beliefs about future wealth serve as reference points when making investment decisions and help generalize the results from Experiments 1 and 2 .

\section{General Discussion}

In Experiments 1-3, we found consistent evidence that people have a positive outlook on their future finances, believing that assets will grow and debt will shrink. While optimistic, these beliefs appear consistent with real world outcomes documented in the PSID. In a follow-up survey conducted in Summer 2020 during the economic crisis associated with the COVID-19 pandemic, we observed greater heterogeneity in beliefs about future wealth, with some individuals believing their assets will grow and other individuals believing their assets will shrink. We examined consequences of these beliefs and found that optimistic beliefs correspond to an increase in risky choices. A comparison of four computational models with variation in reference points supported the hypothesis that beliefs about future asset levels alter decisions by acting as reference points. Specifically, in Experiments 1 and 2, we found optimism increased risk taking by making the small amount of interest in the traditional savings account appear as a loss. These findings were corroborated and generalized in a large-scale survey examining investment decisions about the US stock market.

Our paper relates to prior work examining how experimentally manipulated imagined future wealth frames (i.e., wealthy and poor frames) influence risky decisions in a paired lottery task (Greenberg, 2013). People made riskier decisions in the wealthy frame (vs. poor frame and control), suggesting that imagined financial states can influence risk taking behavior. Our results go beyond this simple demonstration in three important ways. First, we measure beliefs rather than manipulating them. This approach has the benefit of providing insight into the beliefs themselves. 
Second, our methodology allows us to examine whether and how beliefs influence decisions without explicitly drawing attention to the beliefs. In Experiments 1 and 2, questions asking participants to estimate future wealth for a given financial profile and those asking them to make investment decisions for that same profile were separated by a distractor task and presented in the mix of a long series of questions about different financial profiles, making it unlikely that participants would be able to draw direct connections between the two tasks. Third, participants in both the experiments and survey made realistic financial decisions about different investment options, not decisions about simple gambles. This allows us to generalize beyond typical laboratory tasks to examine decisions with greater magnitudes and consequences. However, we note that all of our experiments used hypothetical decisions. It is possible that these types of decisions are more subject to the influence of expectations than inventive-compatible decisions.

One benefit of the particular investment decision we examine in Experiments 1 and 2 is that it allows us to shed light on the recent popularity of prize-linked savings accounts. Our results suggest that one reason that PLS accounts might be gaining popularity is that basic low-risk, lowreturn interest-based savings accounts are unappealing to consumers. If participants evaluate these accounts based on their beliefs about how their assets should grow, a basic savings account might psychologically appear as a loss. Thus, for those who either do not have access to more traditional investment opportunities (e.g., stock market investments) or do not want to engage with those investments for other reasons (e.g., the financial products are too complex), prize-linked savings accounts can serve as an attractive alternative.

In the current work, we explore the relationship between optimistic beliefs and decisions. While investigation of the origin of people's optimistic beliefs is beyond the scope of this paper, belief formation is an important topic in and of itself. Berman, Tran, Lynch Jr, and Zauberman (2016) examined the related question of how people form beliefs about predictions of future slack (i.e., income minus expenses). They found that consumers generally believe that both their income and their expenses will rise in the future, but they tend to underweight future expenses relative to income when making predictions about future slack. Thus, "optimistic" beliefs in that setting might arise from expense neglect. More generally, how people form financial beliefs is an important area for future research.

The ability to plan effectively and make strategic decisions today requires insight into likely 
future outcomes. Thus, predictions about the future are likely to extend beyond the domain of financial decisions to influence other types of choices. For example, predictions about future weight may guide decisions about what foods to eat and how much to exercise, while predictions about future career success may guide choices about how much education to pursue. Recognizing the role of predictions as reference points can help us guide people towards better decisions. Future research should explore the role of predictions as reference points in areas across domains.

\section{Author Contributions}

All authors contributed in a significant way to the manuscript and all authors approved the final manuscript. The authors did not have any conflicts of interest that would have impacted this work.

\section{Appendix A. Supplementary material}

Supplementary material is available online for download. 


\section{References}

Abeler, J., Falk, A., Goette, L., \& Huffman, D. (2011). Reference points and effort provision. American Economic Review, 101(2), 470-92.

Atalay, K., Bakhtiar, F., Cheung, S., \& Slonim, R. (2014). Savings and prize-linked savings accounts. Journal of Economic Behavior \& Organization, 107, 86-106.

Bartling, B., Brandes, L., \& Schunk, D. (2015). Expectations as reference points: Field evidence from professional soccer. Management Science, 61(11), 2646-2661.

Bell, D. E. (1985). Disappointment in decision making under uncertainty. Operations research, 33(1), 1-27.

Berman, J. Z., Tran, A. T., Lynch Jr, J. G., \& Zauberman, G. (2016). Expense neglect in forecasting personal finances. Journal of Marketing Research, 53(4), 535-550.

Broomell, S. B., \& Bhatia, S. (2014). Parameter recovery for decision modeling using choice data. Decision, l(4), 252.

Choi, J. J., Laibson, D., Madrian, B. C., \& Metrick, A. (2009). Reinforcement learning and savings behavior. The Journal of finance, 64(6), 2515-2534.

Coppock, A., \& McClellan, O. A. (2019). Validating the demographic, political, psychological, and experimental results obtained from a new source of online survey respondents. Research \& Politics, 6(1), 2053168018822174.

Glöckner, A., \& Pachur, T. (2012). Cognitive models of risky choice: Parameter stability and predictive accuracy of prospect theory. Cognition, 123(1), 21-32.

Greenberg, A. E. (2013). When imagining future wealth influences risky decision making. Judgment and Decision Making, 8(3), 268-277.

Greenwood, R., \& Shleifer, A. (2014). Expectations of returns and expected returns. The Review of Financial Studies, 27(3), 714-746.

Gul, F., et al. (1991). A theory of disappointment aversion. Econometrica, 59(3), 667-686.

Heath, C., Larrick, R. P., \& Wu, G. (1999). Goals as reference points. Cognitive psychology, 38(1), 79-109.

Kearney, M. S., Tufano, P., Guryan, J., \& Hurst, E. (2010). Making savers winners: An overview of prizelinked savings products (Tech. Rep.). National Bureau of Economic Research.

Kőszegi, B., \& Rabin, M. (2006). A model of reference-dependent preferences. The Quarterly Journal of Economics, 121(4), 1133-1165.

Kőszegi, B., \& Rabin, M. (2007). Reference-dependent risk attitudes. American Economic Review, 97(4), 1047-1073.

Kőszegi, B., \& Rabin, M. (2009). Reference-dependent consumption plans. American Economic Review, 99(3), 909-36. 
Lee, M. D., \& Wagenmakers, E.-J. (2014). Bayesian cognitive modeling: A practical course. Cambridge university press.

Loomes, G., \& Sugden, R. (1986). Disappointment and dynamic consistency in choice under uncertainty. The Review of Economic Studies, 53(2), 271-282.

Malmendier, U., \& Nagel, S. (2011). Depression babies: Do macroeconomic experiences affect risk taking? The quarterly journal of economics, 126(1), 373-416.

Markle, A., Wu, G., White, R., \& Sackett, A. (2018). Goals as reference points in marathon running: A novel test of reference dependence. Journal of Risk and Uncertainty, 56(1), 19-50.

Marzilli Ericson, K. M., \& Fuster, A. (2011). Expectations as endowments: Evidence on reference-dependent preferences from exchange and valuation experiments. The Quarterly Journal of Economics, 126(4), 1879-1907.

Nilsson, H., Rieskamp, J., \& Wagenmakers, E.-J. (2011). Hierarchical bayesian parameter estimation for cumulative prospect theory. Journal of Mathematical Psychology, 55(1), 84-93.

Panel study of income dynamics, public use dataset. (2021). Produced and distributed by the Survey Research Center, Institute for Social Research, University of Michigan, Ann Arbor, MI.

Plummer, M., et al. (2003). Jags: A program for analysis of bayesian graphical models using gibbs sampling. In Proceedings of the 3rd international workshop on distributed statistical computing (Vol. 124).

Pope, D. G., \& Schweitzer, M. E. (2011). Is tiger woods loss averse? persistent bias in the face of experience, competition, and high stakes. American Economic Review, 101(1), 129-57.

Puri, M., \& Robinson, D. T. (2007). Optimism and economic choice. Journal of Financial Economics, 86(1), 71-99.

Rieskamp, J. (2008). The probabilistic nature of preferential choice. Journal of Experimental Psychology: Learning, Memory, and Cognition, 34(6), 1446.

Scheibehenne, B., \& Pachur, T. (2015). Using bayesian hierarchical parameter estimation to assess the generalizability of cognitive models of choice. Psychonomic bulletin \& review, 22(2), 391-407.

Shepperd, J. A., Klein, W. M., Waters, E. A., \& Weinstein, N. D. (2013). Taking stock of unrealistic optimism. Perspectives on Psychological Science, 8(4), 395-411.

Spiegelhalter, D. J., Best, N. G., Carlin, B. P., \& Van Der Linde, A. (2002). Bayesian measures of model complexity and fit. Journal of the royal statistical society: Series b (statistical methodology), 64(4), 583-639.

Stewart, N., Scheibehenne, B., \& Pachur, T. (2018). Psychological parameters have units: A bug fix for stochastic prospect theory and other decision models.

Stott, H. P. (2006). Cumulative prospect theory’s functional menagerie. Journal of Risk and uncertainty, 32(2), 101-130. 
Sussman, A. B., \& Shafir, E. (2012). On assets and debt in the psychology of perceived wealth. Psychological Science, 23(1), 101-108.

Tufano, P., De Neve, J.-E., \& Maynard, N. (2011). Us consumer demand for prize-linked savings: New evidence on a new product. Economics Letters, 111(2), 116-118.

Tversky, A., \& Kahneman, D. (1991). Loss aversion in riskless choice: A reference-dependent model. The quarterly journal of economics, 106(4), 1039-1061.

Tversky, A., \& Kahneman, D. (1992). Advances in prospect theory: Cumulative representation of uncertainty. Journal of Risk and uncertainty, 5(4), 297-323.

Weinstein, N. D. (1980). Unrealistic optimism about future life events. Journal of personality and social psychology, 39(5), 806.

Weinstein, N. D., \& Lachendro, E. (1982). Egocentrism as a source of unrealistic optimism. Personality and Social Psychology Bulletin, 8(2), 195-200.

Wu, G., \& Gonzalez, R. (1996). Curvature of the probability weighting function. Management science, 42(12), 1676-1690. 